2018

\title{
Size-Dependent Inhibitory Effects of Antibiotic Drug Nanocarriers Against Pseudomonas Aeruginosa
}

Feng Ding

Old Dominion University

Preeyaporn Songkiatisak

Old Dominion University

Pavan Kumar Cherukuri

Old Dominion University

Tao Huang

Old Dominion University

Xiao-Hong Nancy Xu

Old Dominion University, xhxu@odu.edu

Follow this and additional works at: https://digitalcommons.odu.edu/chemistry_fac_pubs

Part of the Biochemistry Commons, Nanomedicine Commons, and the Pathogenic Microbiology Commons

\section{Repository Citation}

Ding, Feng; Songkiatisak, Preeyaporn; Cherukuri, Pavan Kumar; Huang, Tao; and Xu, Xiao-Hong Nancy, "Size-Dependent Inhibitory Effects of Antibiotic Drug Nanocarriers Against Pseudomonas Aeruginosa" (2018). Chemistry \& Biochemistry Faculty Publications. 100. https://digitalcommons.odu.edu/chemistry_fac_pubs/100

\section{Original Publication Citation}

Ding, F., Songkiatisak, P., Cherukuri, P. K., Huang, T., \& Xu, X.-H. N. (2018). Size-dependent inhibitory effects of antibiotic drug nanocarriers against Pseudomonas aeruginosa. ACS Omega, 3(1), 1231-1243. doi:10.1021/acsomega.7b01956

This Article is brought to you for free and open access by the Chemistry \& Biochemistry at ODU Digital Commons. It has been accepted for inclusion in Chemistry \& Biochemistry Faculty Publications by an authorized administrator of ODU Digital Commons. For more information, please contact digitalcommons@odu.edu. 


\title{
Size-Dependent Inhibitory Effects of Antibiotic Drug Nanocarriers against Pseudomonas aeruginosa
}

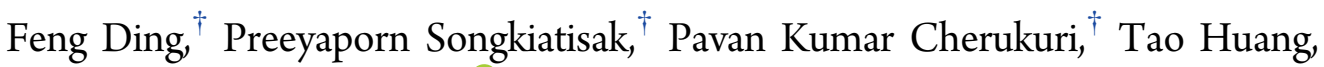 \\ and Xiao-Hong Nancy $\mathrm{Xu}^{*}(0)$
}

Department of Chemistry and Biochemistry, Old Dominion University, Norfolk, Virginia 23529, United States

\section{Supporting Information}

\begin{abstract}
Multidrug membrane transporters (efflux pumps) are responsible for multidrug resistance (MDR) and the low efficacy of therapeutic drugs. Noble metal nanoparticles (NPs) possess a high surface-area-to-volume ratio and sizedependent plasmonic optical properties, enabling them to serve both as imaging probes to study sized-dependent $\mathrm{MDR}$ and as potential drug carriers to circumvent MDR and enhance therapeutic efficacy. To this end, in this study, we synthesized three different sizes of silver nanoparticles (Ag NPs), $2.4 \pm 0.7,13.0$ \pm 3.1 , and $92.6 \pm 4.4 \mathrm{~nm}$, functionalized their surface with a monolayer of 11amino-1-undecanethiol (AUT), and covalently conjugated them with antibiotics (ofloxacin, Oflx) to prepare antibiotic drug nanocarriers with conjugation ratios of $8.6 \times 10^{2}, 9.4 \times 10^{3}$, and $6.5 \times 10^{5}$ Oflx molecules per NP, respectively. We purified and characterized the nanocarriers and developed cell culture medium in which the cells grew normally and the nanocarriers were stable (non-aggregated), to quantitatively study the size, dose, and efflux pump (MexAB-OprM) dependent inhibitory effect of the nanocarriers against two strains of Pseudomonas aeruginosa, WT (normal expression of MexAB-OprM) and $\triangle \mathrm{ABM}$ (deletion of MexAB-OprM). We found that the inhibitory effect of these nanocarriers highly depended on the sizes of NPs, the doses of antibiotic, and the expression of MexAB-OprM. The same amount of Oflx on the largest nanocarriers $(92.6 \pm 4.4 \mathrm{~nm})$ showed the highest inhibitory effect (the lowest minimal inhibitory concentration) against P. aeruginosa. Surprisingly, the smallest nanocarriers $(2.4 \pm 0.7 \mathrm{~nm})$ exhibited a lower inhibitory effect than free Oflx. The results suggest that size-dependent multivalent effects, the distribution and localization of Oflx (pharmacodynamics), and the efflux of Oflx all play a role in the inhibitory effects. Control experiments using three sizes of $\mathrm{AgMUNH}_{2} \mathrm{NPs}$ (absence of Oflx) showed that these NPs do not exhibit any significant inhibitory activity toward both strains. These new findings demonstrate the need for and possibility of designing optimal sized antibiotic nanocarriers to achieve the highest efficacy against $P$. aeruginosa.
\end{abstract}

\section{INTRODUCTION}

All living organisms are equipped with multi-substrate extrusion systems (membrane transporters or efflux pumps) to selectively extrude a wide range of substrates out of live cells. ${ }^{1,2}$ Such selfprotective efflux machinery resists the accumulation of structurally and functionally unrelated noxious compounds inside the cells and causes multidrug resistance (MDR) and low efficacy of therapeutic drugs (e.g., antibiotics). ${ }^{3-7} \mathrm{MDR}$ is responsible for the creation of superbugs and the urgent need to develop new classes of antibiotics against bacterial pathogens. ${ }^{7,8}$ Multidrug membrane transporters have been identified as targets to increase the efficacy of therapeutic drugs and the effectiveness of treatment. ${ }^{7-9}$ However, despite extensive studies over decades, the molecular mechanisms of MDR and the efflux functions of multidrug membrane transporters remain elusive. $4,7,8,10,11$

Pseudomonas aeruginosa (a ubiquitous Gram-negative bacterium) has become one of the major opportunistic human pathogens and a leading cause of nosocomial infections. ${ }^{10,12-15}$ $P$. aeruginosa possesses several multidrug membrane transporters (efflux pumps). ${ }^{16-20}$ These multidrug membrane transporters can selectively extrude a wide variety of structurally and functionally unrelated antibiotics out of the bacterial cells, which causes MDR and difficulty in treating infections. $^{4,10,11,20,21}$ For example, MexAB-OprM is the primary membrane transporter found in wild-type (WT) P. aeruginosa, and it consists of two inner membrane proteins (MexA and $\mathrm{MexB})$ and one outer membrane protein (OprM). ${ }^{22-24}$ The MexAB-OprM transporter of $P$. aeruginosa can extrude an array of antibiotics (e.g., ofloxacin, azthreonam, chloramphenicol, and gentamicin) out of these cells, leading to a lower accumulation of antibiotics inside the cells and a higher minimal inhibitory concentration (MIC) against P. aeruginosa. ${ }^{25}$ Notably, the sizes, structures, and chemical properties of antibiotics (pump substrates) vary drastically.

Nanomaterials possess distinctive physiochemical properties, such as high surface-to-volume ratios and small sizes. Studies have shown that these distinctive properties could enable

Received: December 7, 2017

Accepted: January 12, 2018

Published: January 30, 2018 
nanomaterials to serve as drug carriers to increase the payload of therapeutic agents and hence enhance the efficacy of localization for targeted therapy. ${ }^{26-28}$ However, systematic and quantitative studies of the dependence of efficacy of drug nanocarrier on their physicochemical properties (e.g., sizes) and their underlying molecular mechanisms remain largely unexplored. Furthermore, it remains very challenging to characterize the physicochemical properties of individual nanocarriers in situ in real time at single NP resolution. Moreover, current studies have primarily focused on polymer-based nanocarriers (e.g., vesicles) for treating eukaryotic cells, with only few studies examining noble metal NP-based antibiotic nanocarriers for inhibiting the growth of bacteria. ${ }^{26-29}$

Noble metal NPs (e.g., Ag NPs) exhibit sized-dependent plasmonic optical properties, exceptionally high Rayleigh scattering, and photostability (non-photobleaching and nonblinking). ${ }^{29-36}$ We have directly imaged and characterized single noble metal NPs (Ag or Au NPs) in situ in real time using dark-field optical microscopy and spectroscopy (DFOMS)..$^{34,35,37-39}$ We have used size-dependent localized surface plasmon resonance (LSPR) spectra of single NPs to determine the sizes of individual NPs in solution, single live cells, and embryos in situ in real time, and we have directly measured the sizes of single NPs as they are transported in and out of single live cells in real time..$^{29,32-36,40-43}$ We have demonstrated that $\mathrm{Ag}$ and $\mathrm{Au}$ NPs can serve as photostable nanophotonic optical probes for sensing and imaging single molecules and dynamics events of interest in single live cells and embryos over time. ${ }^{34,36-41,43-47}$ For instance, we have used the intrinsic optical properties of single Ag and Au NPs to study the size-dependent transport dynamics of single membrane transporters and the size-dependent permeability of cellular membranes of single live cells induced by antibiotics (e.g., aztreonam, chloramphenicol) at nanometer spatial resolution and millisecond temporal resolution. ${ }^{36,40,41,43}$

In this study, we synthesized, purified, and characterized three different sizes of Ag NP-based antibiotic nanocarriers (2.4 $\pm 0.7,13.0 \pm 3.1$, and $92.6 \pm 4.4 \mathrm{~nm})$. We quantitatively studied the size, dose, and efflux pump (MexAB-OprM) dependent inhibitory effects (susceptibility) of the nanocarriers against two strains of $P$. aeruginosa, WT (normal expression of MexAB-OprM) and $\triangle A B M$ (deletion of MexAB-OprM), aiming to study not only the dependence of the therapeutic effects of antibiotics on the sizes of the nanocarriers but also the dependence of the efflux function of the MexAB-OprM multidrug membrane transporter of $P$. aeruginosa on the sizes of the nanocarriers. We used single Ag NPs both as antibiotic nanocarriers and as imaging probes to study their MDR dependent therapeutic effects, aiming to rationally design nanocarriers that not only can increase the local payload of therapeutic agents to target bacteria, but also can evade multidrug efflux pumps and circumvent MDR, thus achieving higher efficacy and lower therapeutic side effects. To our knowledge, drug nanocarriers have not yet been reported for the study of MDR and the efflux function of a multidrug membrane transporter in bacteria.

\section{RESULTS AND DISCUSSION}

Synthesis and Characterization of Three Different Sized Ag NPs. We synthesized and purified three different sized Ag NPs, as described in Materials and Methods and as reported previously by us. ${ }^{32,37,38,47,48}$ Representative TEM images (Figure 1A: a-c) and histograms of size distribution
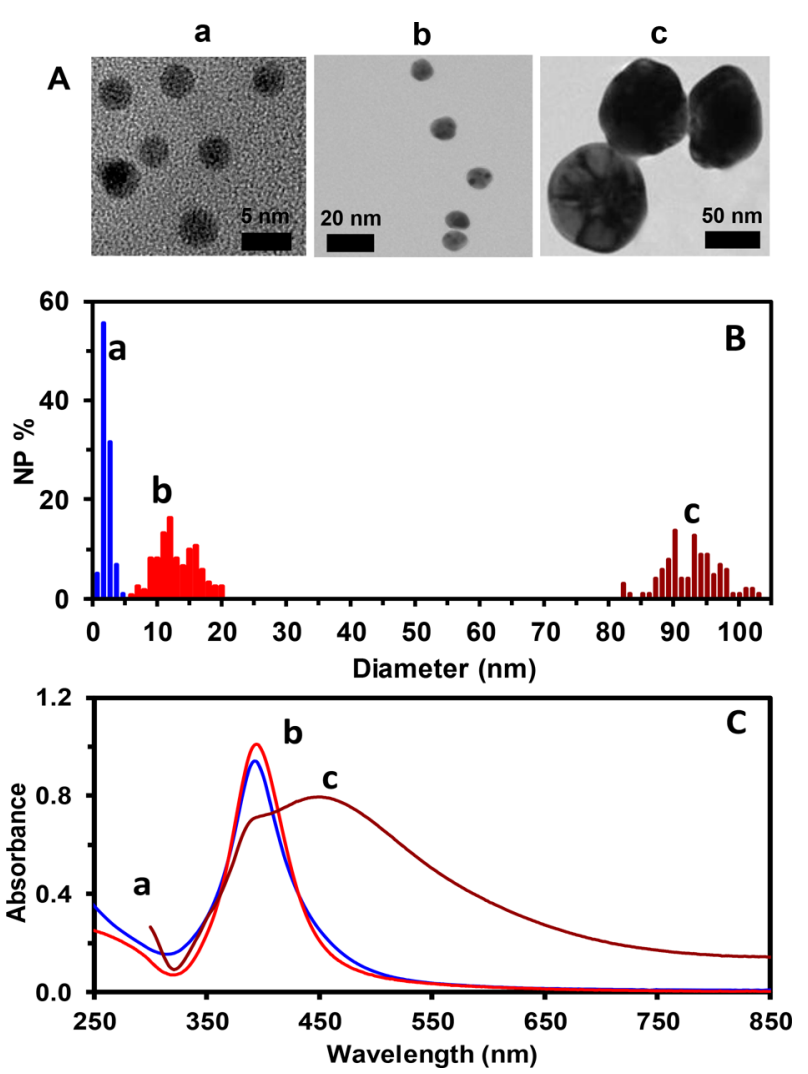

Figure 1. Characterization of sizes, shapes, and plasmonic optical properties of three different sized Ag NPs. (A) HRTEM images of single Ag NPs and (B) histograms of their size distributions show nearly spherical shaped NPs with average diameters of (a) $2.4 \pm 0.7$, (b) $13.0 \pm 3.1$, and (c) $92.6 \pm 4.4 \mathrm{~nm}$. (C) UV-vis absorption spectra of the NPs in DI water show the peak absorption (full width at halfmaximum), $\lambda_{\max }$ (fwhm), at (a) 392 (57), (b) 395 (59), and (c) 450 $\mathrm{nm}$ with a shoulder peak of $390 \mathrm{~nm}$, respectively.

(Figure 1B: a-c) of the three different NP samples show nearly spherical shaped NPs with diameters of $2.4 \pm 0.7,13.0 \pm 3.1$, and $92.6 \pm 4.4 \mathrm{~nm}$, respectively. Notably, the shapes of the smallest NPs are the closest to spherical. In contrast, the shapes of the largest NPs are polygonal (the least spherical). The diameters of oval and irregular shaped NPs were determined by averaging the length and width of the NPs.

We characterized the plasmonic absorption and scattering of Ag NP solutions using UV-vis absorption spectroscopy. UVvis absorption spectra of three different sized NPs with diameters of $2.4 \pm 0.7,13.0 \pm 3.1$, and $92.6 \pm 4.4 \mathrm{~nm}$ show that their peak wavelengths with full width at half-maximum, $\lambda_{\max }$ (fwhm), are 392 (57), 395 (59), and 450 (182) nm, respectively. We did not observe any shoulder peak for NPs with diameters of either $2.4 \pm 0.7$ or $13.0 \pm 3.1 \mathrm{~nm}$, further demonstrating that they are nearly spherical. In contrast, we observed one shoulder peak at $390 \mathrm{~nm}$ for the $92.6 \pm 4.4 \mathrm{~nm}$ diameter NPs, which is most likely attributed to the in-plane quadrupole resonance of the NPs generated by transverse collective oscillation of the surface electrons between the edges of the NPs. Notably, the TEM images of the NPs (Figure 1A: c) indeed show that they are polygonal with sharp edges.

Synthesis and Characterization of Antibiotic Nanocarriers (AgMUNH-Oflx NPs). We functionalized the well purified and characterized Ag NPs with a monolayer of 11amino-1-undecanethiol (AUT) by replacing the citrate 

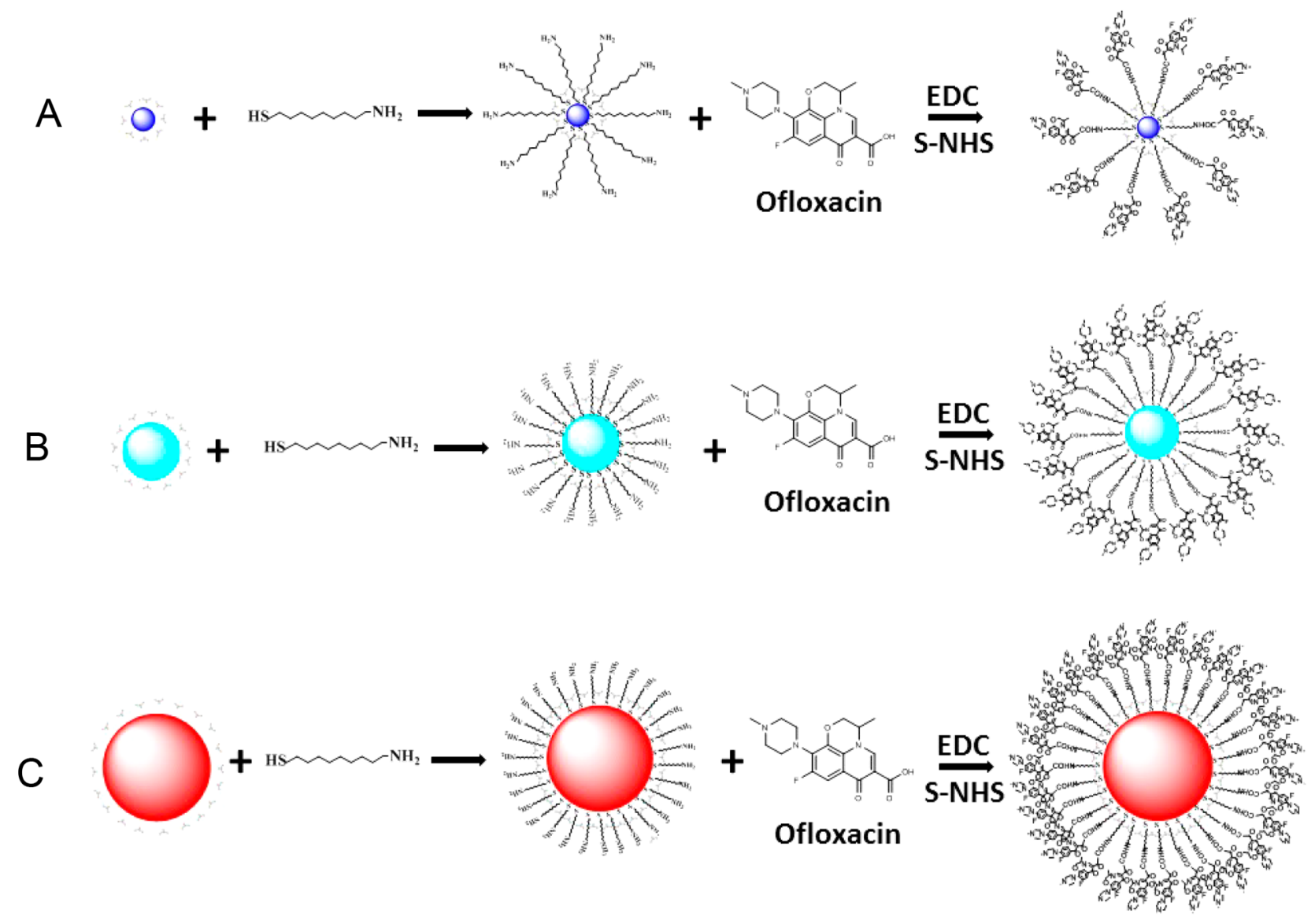

Figure 2. Schematic illustration of synthesis of three different sized antibiotic nanocarriers. The surfaces of (A) $2.4 \pm 0.7$, (B) $13.0 \pm 3.1$ and (C) $92.6 \pm 4.4 \mathrm{~nm} \mathrm{Ag}$ NPs were functionalized with a monolayer of AUT using the interaction of the thiol groups $(-\mathrm{SH})$ of AUT with the surface of Ag NPs to prepare AgMUNH $\mathrm{AP}_{2}$ NP. The amine group of AUT attached onto the surface of Ag NPs was then conjugated with the carboxyl group of the Oflx via a peptide bond using EDC and sulfo-NHS as mediators to prepare AgMUNH-Oflx NPs (antibiotic nanocarriers).

molecules electrostatically adsorbed on the surface of the NPs with AUT via the interaction of thiol groups of AUT with the $\mathrm{NPs}$ to prepare $\mathrm{AgMUNH}_{2} \mathrm{NPs}$, as presented in the Materials and Methods and Figure 2. We washed the $\mathrm{AgMUNH}_{2} \mathrm{NPs}$ thoroughly with nanopure water to remove excess AUT using centrifugation. We then covalently conjugated the amine groups of each size of $\mathrm{AgMUNH}_{2} \mathrm{NPs}$ with the carboxyl group of ofloxacin (Oflx) via a peptide bond using a two-step method with EDC and sulfo-NHS as mediators to prepare antibiotic nanocarriers (AgMUNH-Oflx NPs), as illustrated in Figure 2.

We purified the drug nanocarriers (AgMUNH-Oflx NPs) by thoroughly washing them with deionized (DI) water, and we characterized the conjugation ratios of Oflx molecules to the NPs using UV-vis absorption spectroscopy, as shown in Figure 3 and Table 1. The absorption spectrum of $2.4 \pm 0.7 \mathrm{~nm} \mathrm{Ag}$ NPs (Figure 3A: a) shows a plasmonic absorption peak wavelength of $390 \mathrm{~nm}$ with a fwhm of $55 \mathrm{~nm}$. After the surface of the NPs was functionalized with a monolayer of AUT, the refractivity of the NPs decreased and their dielectric constant increased, leading to a red-shifted and broader plasmonic absorption spectrum. Thus, the plasmonic absorption spectrum of $\mathrm{AgMUNH}_{2}$ NPs (Figure 3A: b) shows a peak wavelength of $413 \mathrm{~nm}$ and a fwhm of $132 \mathrm{~nm}$. Upon conjugation of Oflx with the $\mathrm{AgMUNH}_{2}$ NPs, we observed both the distinctive absorption peak wavelengths of Oflx at 288 and $331 \mathrm{~nm}$ and the plasmonic peak absorption of the NPs at $416 \mathrm{~nm}$ for the nanocarriers (AgMUNH-Oflx NPs). We subtracted the absorption spectrum of $\mathrm{AgMUNH}_{2}$ NPs from that of AgMUNH-Oflx NPs and determined the concentration of Oflx covalently attached onto the nanocarriers using the absorbance at $288 \mathrm{~nm}$. We used the plasmonic peak absorbance of NPs in the same nanocarriers to determine the concentration of NPs. We divided the Oflx concentration of the nanocarrier by the NP concentration of the same nanocarrier solution to quantitatively characterize the conjugation ratio of Oflx molecules to NPs, showing $8.6 \times 10^{2}$ Oflx molecules/NP for the $2.4 \pm 0.7 \mathrm{~nm}$ Ag NPs. Using a close-packed model with the footprint of each AUT molecule of $0.214 \times 0.214 \mathrm{~nm}^{2}$ on the surface of the $\mathrm{NP},{ }^{38}$ we found that the smooth surface area of a perfectly spherical NP with a diameter of $2.4 \mathrm{~nm}$ could only accommodate 395 Oflx molecules/NP. The 2-fold higher payload of $8.6 \times 10^{2}$ Oflx molecules/NP could be attributed to the rough surface and irregular shape of the NPs.

The absorption spectrum of the $13.0 \pm 3.1 \mathrm{~nm} \mathrm{Ag} \mathrm{NPs}$ (Figure 3B: a) shows a plasmonic absorption peak wavelength at $399 \mathrm{~nm}$ and a fwhm of $58 \mathrm{~nm}$. After their surface was functionalized with a monolayer of AUT, their plasmonic absorption spectrum (Figure 3B: b) red-shifted and showed a peak wavelength of $413 \mathrm{~nm}$ and a fwhm of $132 \mathrm{~nm}$. After the $\mathrm{AgMUNH}_{2}$ NPs were conjugated with Oflx, the plasmonic absorption spectrum of AgMUNH-Oflx NPs (nanocarriers) exhibited both the distinctive absorption peak wavelengths of Oflx at 288 and $331 \mathrm{~nm}$ as well as the plasmonic peak 

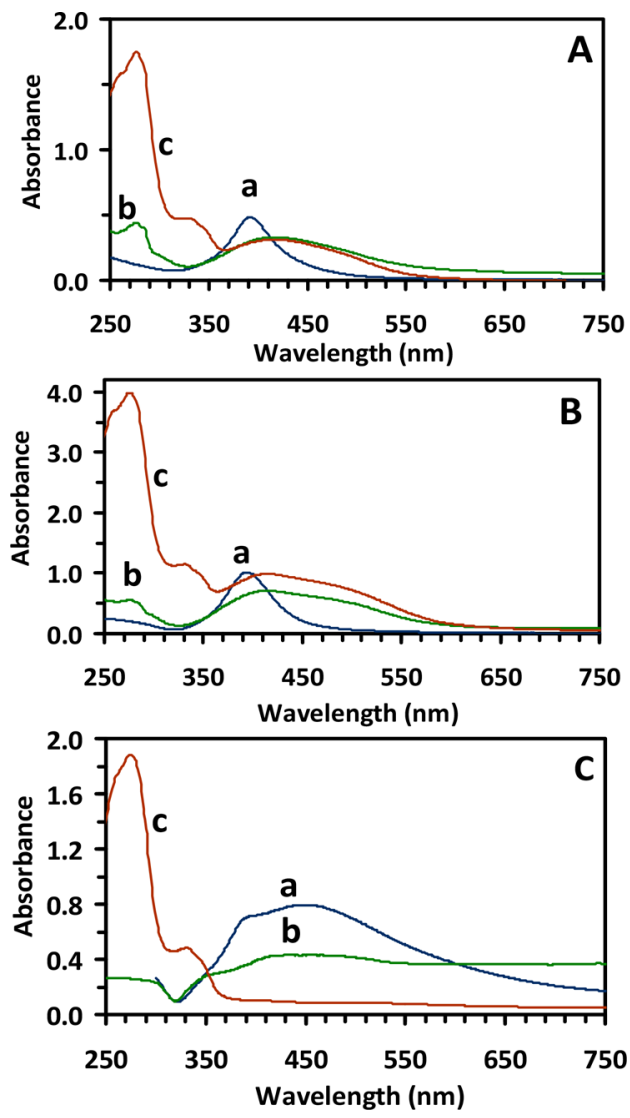

Figure 3. Characterization of conjugation ratios of Oflx molecules with NPs for three different sized Ag NPs using UV-vis absorption spectroscopy. (A) UV-vis absorption spectra of (a) $2.4 \pm 0.7 \mathrm{~nm} \mathrm{Ag}$ NPs, (b) $\mathrm{AgMUNH}_{2} \mathrm{NPs}$, and (c) AgMUNH-Oflx NPs show plasmonic absorption peak wavelengths $\left(\lambda_{\max }\right)$ of the NPs at 392, 413, and $416 \mathrm{~nm}$, respectively. (B) UV-vis absorption spectra of (a) $13.0 \pm$ $3.1 \mathrm{~nm} \mathrm{Ag} \mathrm{NPs,} \mathrm{(b)} \mathrm{AgMUNH}_{2} \mathrm{NPs}$, and (c) AgMUNH-Oflx NPs show plasmonic absorption $\lambda_{\max }$ of the NPs at 394, 414, and $418 \mathrm{~nm}$, respectively. (C) UV-vis absorption spectra of (a) $92.6 \pm 4.4 \mathrm{~nm} \mathrm{Ag}$ NPs, (b) $\mathrm{AgMUNH}_{2} \mathrm{NPs}$, and (c) AgMUNH-Oflx NPs show plasmonic absorption $\lambda_{\max }$ of the NPs at 450,453 , and $486 \mathrm{~nm}$, respectively. Note that signature absorption $\lambda_{\max }$ of Oflx at 288 and $331 \mathrm{~nm}$ were observed only in (c) for the three sized nanocarriers, showing the conjugation of Oflx with the NPs.

Table 1. Determination of the Conjugation Ratios of Ofloxacin (Oflx) Molecules per NP for Three Different Sized Drug Nanocarriers

$\begin{array}{rccc}\text { NP diameter }(\mathrm{nm}) & C_{\mathrm{NPs}}{ }^{a}(\mathrm{nM}) & C_{\mathrm{Offx}}{ }^{b}(\mu \mathrm{M}) & R_{\mathrm{Oflx} / \mathrm{NP}}{ }^{c} \\ 2.4 \pm 0.7 & 50 & 43.2 & 8.6 \times 10^{2} \\ 13.0 \pm 3.1 & 3.3 & 31.1 & 9.4 \times 10^{3} \\ 92.6 \pm 4.4 & 0.030 & 19.4 & 6.5 \times 10^{5}\end{array}$

${ }^{a}$ Plasmonic absorbance of the drug nanocarriers (AgMUNH-Oflx $\mathrm{NPs}$ ) at $\lambda_{\max }$ of 416,418 , and $486 \mathrm{~nm}$ was used to determine the concentration of the $2.4 \pm 0.7,13.0 \pm 3.1$, and $92.6 \pm 4.4 \mathrm{~nm} \mathrm{NPs}$, respectively. ${ }^{b} C_{\mathrm{Oflx}}$ was determined by subtracting the UV-vis absorption spectra of $\mathrm{AgMUNH}_{2} \mathrm{NPs}$ from that of AgMUNH-Oflx NPs and dividing the peak absorbance of the subtracted UV-vis spectra at $288 \mathrm{~nm}$ by the molar absorptivity $\left(\varepsilon_{288 \mathrm{~nm}}\right)$ of Oflx, $7.8 \times 10^{3}$ $\mathrm{M}^{-1} \mathrm{~cm}^{-1}$. ${ }^{c}$ Conjugation ratio of the number of Oflx molecules per NP was calculated by dividing the concentration of Oflx by the concentration of NPs for the same solution of AgMUNH-Oflx NPs for the $2.4 \pm 0.7,13.0 \pm 3.1$, and $92.6 \pm 4.4 \mathrm{~nm} \mathrm{NPs}$, respectively. absorption of NPs at $418 \mathrm{~nm}$ for the nanocarriers (AgMUNHOflx NPs). Using the same approaches as described above, we quantitatively characterized the conjugation ratio of $\mathrm{Oflx}$ molecules to NPs as $9.4 \times 10^{3}$ Oflx molecules/NP for the $13.0 \pm 3.1 \mathrm{~nm} \mathrm{NPs}$, which is nearly equal to the maximum number of AUT molecules $\left(1.2 \times 10^{4}\right.$ molecules $)$ that could be closely packed on the surface of a spherical NP with a diameter of $13 \mathrm{~nm}$, as determined by the close-packed model.

The absorption spectrum of the $92.6 \pm 4.4 \mathrm{~nm} \mathrm{Ag} \mathrm{NPs}$ (Figure 3C: a) shows a plasmonic absorption peak wavelength at $450 \mathrm{~nm}$. After their surface was functionalized with a monolayer of AUT, the peak wavelength of the plasmonic absorption spectrum red-shifted to $453 \mathrm{~nm}$ (Figure 3C: b).

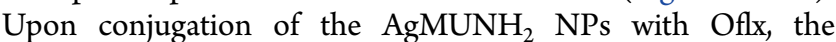
plasmonic absorption spectrum of AgMUNH-Oflx NPs exhibited both the distinctive absorption peak wavelengths of Oflx at 288 and $331 \mathrm{~nm}$ as well as a further red-shifted plasmonic peak absorption of the NPs to $500 \mathrm{~nm}$. Using the same approaches described above, we quantitatively characterized the conjugation ratio of Oflx to the NPs as $6.5 \times 10^{5}$ Oflx molecules/NP for the $92.6 \pm 4.4 \mathrm{~nm} \mathrm{NPs,} \mathrm{which} \mathrm{is}$ approximately equal to the maximum number of AUT molecules $\left(5.9 \times 10^{5}\right.$ molecules $)$ that could be closely packed on the surface of a perfectly spherical NP with a diameter of $92.6 \mathrm{~nm}$, as determined by the close-packed model.

Stability of Drug Nanocarriers (AgMUNH-Oflx NPs) in Cell Culture Medium. In order to study the dependence of the inhibitory effects of these antibiotic nanocarriers against $P$. aeruginosa on the sizes of NPs and doses of antibiotic, it is crucial that the nanocarriers remain stable (non-aggregated) in cell culture medium and that their sizes and doses remain unchanged over the entire duration of the cell culture experiment. If the nanocarriers aggregate in the cell culture medium, then their sizes and doses would change over time, making a study of their size and dose dependent inhibitory effects unreliable.

Therefore, we first characterized the stability (nonaggregation) of each size of drug nanocarriers (AgMUNHOflx NPs) in a commonly used standard LB medium ( $1 \%$ tryptone, $0.5 \%$ yeast extract, and $0.5 \% \mathrm{NaCl}$ in $\mathrm{DI}$ water, $\mathrm{pH}=$ 7.2) over $24 \mathrm{~h}$ using UV-vis absorption spectra. Unfortunately, none of the nanocarriers at the desired concentration were stable in this standard medium.

We then reduced the concentration of $\mathrm{NaCl}$ to $0.1 \%$ and characterized the stability (non-aggregation) of the drug nanocarriers in the modified medium ( $1 \%$ tryptone, $0.5 \%$ yeast extract, and $0.1 \% \mathrm{NaCl}$ in DI water, $\mathrm{pH}=7.2$ ) over $24 \mathrm{~h}$ using UV-vis absorption spectroscopy. The results in Figure 4 show that the absorption spectra of the nanocarriers remain unchanged over $24 \mathrm{~h}$, indicating that the nanocarriers with $\mathrm{Ag}$ $\mathrm{NP}$ diameters of $2.4 \pm 0.7,13.0 \pm 3.1$, and $92.6 \pm 4.4 \mathrm{~nm}$ and concentrations of $6.0 \mathrm{nM}, 0.8 \mathrm{nM}$, and $7 \mathrm{pM}$ were stable (nonaggregated) in the modified medium over $24 \mathrm{~h}$, respectively.

Suitability of the Modified LB Medium for Cell Culture. To ensure that the modified cell culture medium is well suited for culturing healthy cells as their standard cell culture medium, we pre-cultured the cells (WT, $\triangle \mathrm{ABM}$, and nalB-1) in the standard medium for $12 \mathrm{~h}$. We then cultured the pre-cultured cells in the standard medium and the modified medium and measured the growth curves of the cells over time. The results show that the growth curves of the cells cultured in the standard medium (Figure S1-a) and the modified medium 

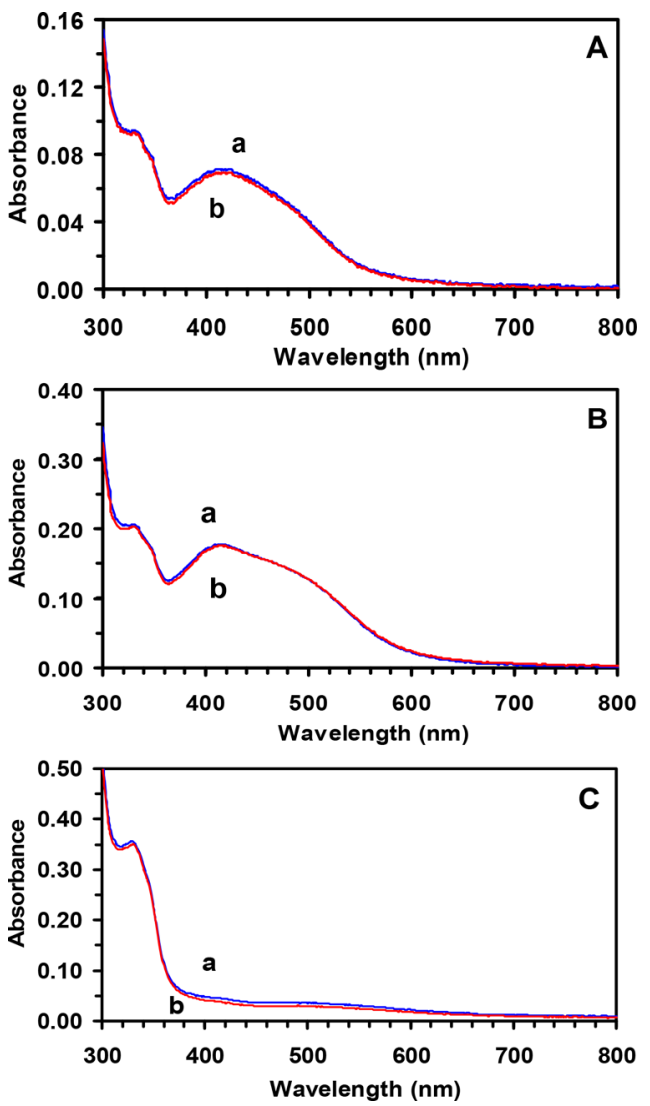

Figure 4. Characterization of the stability (non-aggregation) of three sized antibiotic nanocarriers (AgMUNH-Oflx NPs) in the modified LB medium using UV-vis absorption spectroscopy. The UV-vis absorption spectra of $6 \mathrm{nM}, 0.8 \mathrm{nM}$, and $7 \mathrm{pM}$ AgMUNH-Oflx NPs for the Ag NPs with diameters of (A) $2.4 \pm 0.7$, (B) $13.0 \pm 3.1$, and (C) $92.6 \pm 4.4 \mathrm{~nm}$ in the modified LB medium at (a) 0 and (b) $24 \mathrm{~h}$ remain essentially unchanged over time, which indicates that the nanocarriers are stable (non-aggregated) in this medium over $24 \mathrm{~h}$.

(Figure S1-b) are the same, which demonstrates that the modified medium is well suited for culturing these cells.

We further characterized the viability of the cells that had been cultured in the standard and modified medium over $12 \mathrm{~h}$ using live/dead BacLight assay. Representative optical and fluorescence images of the cultured cells show that more than 99\% of the cells cultured in the standard and modified LB medium over time exhibit SYTO9 green fluorescence and they are viable (Figure S2). The results further demonstrate that the modified medium can be used to replace the standard medium to culture these cells.

Moreover, we characterized the efflux function of MexABOprM by probing the MexAB-OprM dependent accumulation kinetics of intracellular ethidium bromide $(\mathrm{EtBr})$ in live cells (WT, $\triangle \mathrm{ABM}$, and nalB-1). The experiments were conducted in parallel. EtBr shows a low fluorescence intensity outside the cells. As EtBr enters the cells and intercalates with DNA, its fluorescence intensity increases $\sim 10$ times. ${ }^{49}$ Thus, the fluorescence intensity of $\mathrm{EtBr}$ has been widely used to characterize the efflux function of multidrug membrane transporters in live cells in real time using fluorescence spectroscopy. ${ }^{33,45,50-54}$ The results in Figure S3 show that the fluorescence intensity of $\mathrm{EtBr}$ incubated with $\triangle \mathrm{ABM}$ cells (deletion of MexAB-OprM) rapidly increases with time (Figure $\mathrm{S} 3-\mathrm{a})$, whereas the fluorescence intensity of $\mathrm{EtBr}$ incubated with WT cells (normal expression of MexAB-OprM) increases slightly over time (Figure S3-b) and the fluorescence intensity of $\mathrm{EtBr}$ incubated with nalB-1 cells (overexpression of MexABOprM) remains essentially unchanged over time (Figure S3-c). These results show the high dependence of the accumulation kinetics of intracellular EtBr on the expression level of MexABOprM. The cells $(\triangle \mathrm{ABM})$ with deletion of MexAB-OprM exhibit the highest accumulation rate of intracellular EtBr, and the cells (nalB-1) with over-expression of MexAB-OprM show the lowest accumulation rate of intracellular $\mathrm{EtBr}$, indicating that MexAB-OprM extrudes EtBr out of the cells, which leads to the lowest accumulation of intracellular $\mathrm{EtBr}$ in nalB-1 cells. The accumulation rate of $\mathrm{EtBr}$ incubated with cells cultured in either the standard medium (Figure S3-A) or the modified medium (Figure S3-B) is the same, further demonstrating that the modified medium is well suited to culture healthy cells with a fully functioning efflux pump (MexAB-OprM).

Dose, Size, and MexAB-OprM Dependent Inhibitory Effects of Drug Nanocarriers (AgMUNH-Oflx NPs). We cultured the cells (WT or $\triangle \mathrm{ABM}$ ) in the modified medium containing a dilution series of Oflx alone, each given sized drug nanocarrier (AgMUNH-Oflx NPs), and $\mathrm{AgMUNH}_{2} \mathrm{NPs}$ (absence of Oflx, control experiments) by inoculating $10^{4}$ pre-cultured cells into the medium and vigorously shaking the solution $\left(200 \mathrm{rpm}, 37^{\circ} \mathrm{C}\right.$ ) over $17 \mathrm{~h}$.

The dilution series contains $0,0.20,0.40,0.60,0.80,1.08$, 1.62 , and $2.16 \mu \mathrm{M}$ free Oflx (Figure $5 \mathrm{~A}$ ) or Oflx conjugated with the NPs (AgMUNH-Oflx NPs) for WT cells (Figure 5B$\mathrm{D}: \mathrm{b}-\mathrm{h})$, which is correlated with the concentration of the nanocarrier (NP concentration) as follows: (Figure 5B: b-h) $0.23,0.463,0.695,0.917,1.25,1.88$, and $2.50 \mathrm{nM}$ for $2.4 \pm 0.7$ $\mathrm{nm}$ NPs with a conjugation ratio of $8.6 \times 10^{2}$ Oflx molecules per NP; (Figure 5C: b-h) $2.12 \times 10^{-2}, 4.24 \times 10^{-2}, 6.36 \times$ $10^{-2}, 8.48 \times 10^{-2}, 0.114,0.172$, and $0.229 \mathrm{nM}$ for $13.0 \pm 3.1$ $\mathrm{nm}$ NPs with a conjugation ratio of $9.4 \times 10^{3}$ Oflx molecules per NP; and (Figure 5D: b-h) 0.309, 0.618, 0.926, 1.24, 1.67, 2.50, and $3.34 \mathrm{pM}$ for $92.6 \pm 4.4 \mathrm{~nm}$ NPs with a conjugation ratio of $6.5 \times 10^{5}$ Oflx molecules per NP. The control experiments include the medium alone (absence of cells, Figure 5A-D: a) and WT cells cultured under the same conditions and at the same time in the medium containing $2.50 \mathrm{nM}, 0.229$ $\mathrm{nM}$, or $3.34 \mathrm{pM} \mathrm{AgMUNH}_{2}$ NPs (in the absence of Oflx, Figure $5 B-D:$ i) for the $2.4 \pm 0.7,13.0 \pm 3.1$, or $92.6 \pm 4.4 \mathrm{~nm}$ NPs, respectively.

The dilution series contains 0, 0.020, 0.040, 0.060, 0.080, $0.11,0.14,0.28 \mu \mathrm{M}$ free Oflx (Figure 5E) or Oflx conjugated with the NPs (AgMUNH-Oflx NPs) (Figure 5F-H) for $\triangle \mathrm{ABM}$, which is correlated with the concentration of the nanocarrier (NP concentration) as follows: (Figure 5F: $\mathrm{k}-\mathrm{q}$ ) $2.32 \times 10^{-2}, 4.63 \times 10^{-2}, 6.95 \times 10^{-2}, 9.27 \times 10^{-2}, 0.127$, 0.162 , and $0.324 \mathrm{nM}$ for $2.4 \pm 0.7 \mathrm{~nm}$ NPs with a conjugation ratio of $8.6 \times 10^{2}$ Oflx molecules per NP; (Figure 5G: $\mathrm{k}-\mathrm{q}$ ) $2.12 \times 10^{-3}, 4.24 \times 10^{-3}, 6.36 \times 10^{-3}, 8.48 \times 10^{-3}, 1.48 \times 10^{-2}$, and $2.97 \times 10^{-2} \mathrm{nM}$ for $13.0 \pm 3.1 \mathrm{~nm}$ NPs with a conjugation ratio of $9.4 \times 10^{3}$ Oflx molecules per NP; and (Figure $5 \mathrm{H}$ : kq) $3.09 \times 10^{-2}, 6.18 \times 10^{-2}, 9.26 \times 10^{-2}, 0.124,0.170,0.216$, and $0.432 \mathrm{pM}$ for $92.6 \pm 4.4 \mathrm{~nm}$ NPs with a conjugation ratio of $6.5 \times 10^{5}$ Oflx molecules per NP. The control experiments include the medium alone (absence of cells, Figure 5E-H: j) and $\triangle \mathrm{ABM}$ cells cultured under the same conditions and at the same time in the medium containing $0.324 \mathrm{nM}, 2.97 \times 10^{-2}$ $\mathrm{nM}$, or $0.432 \mathrm{pM} \mathrm{AgMUNH} \mathrm{APs}_{2}$ (in the absence of Oflx, 


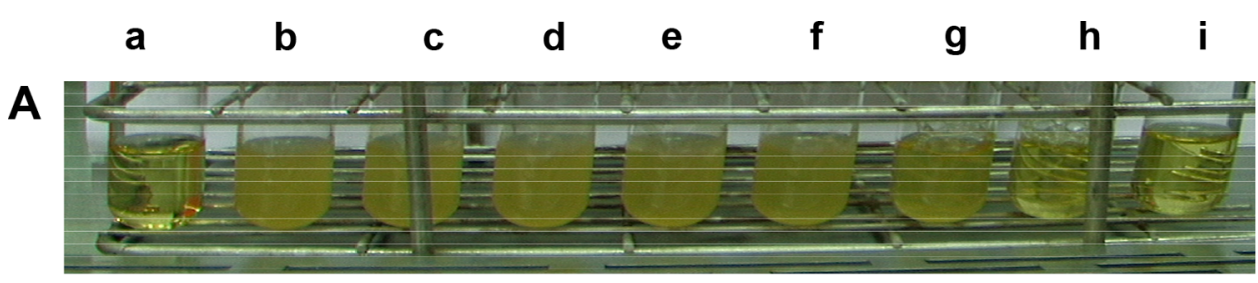

B

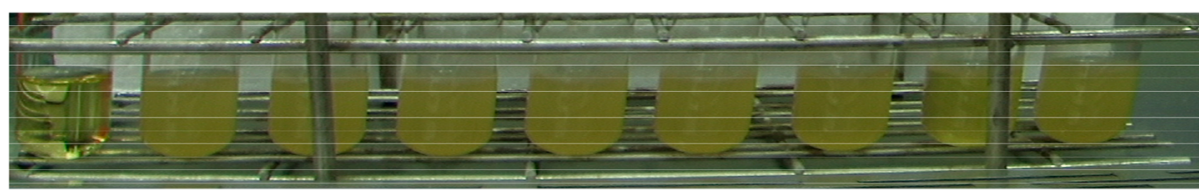

C

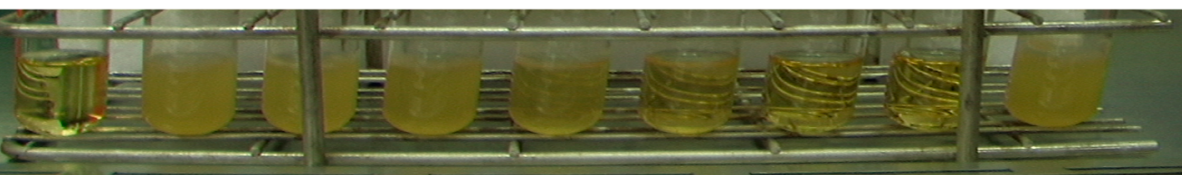

D
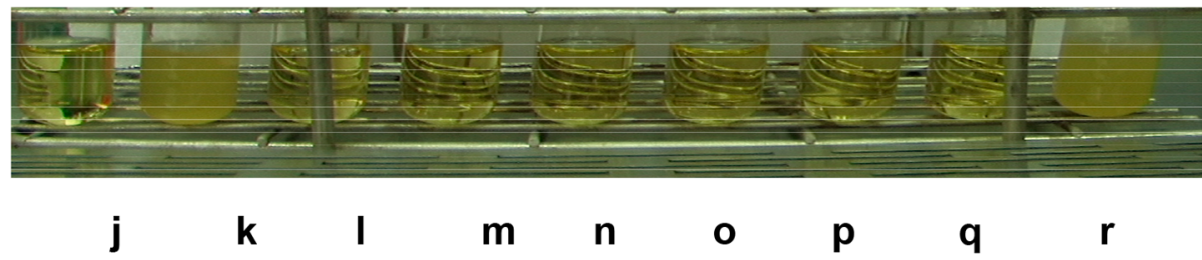

E

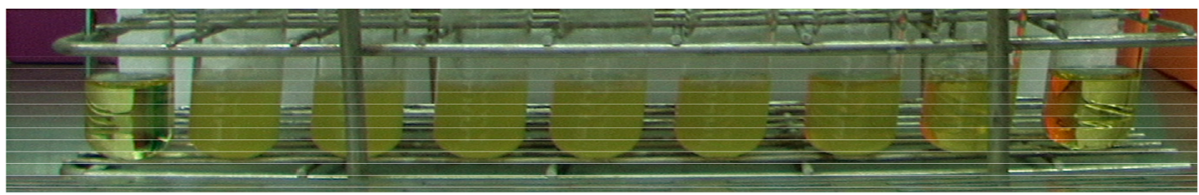

$\mathbf{F}$

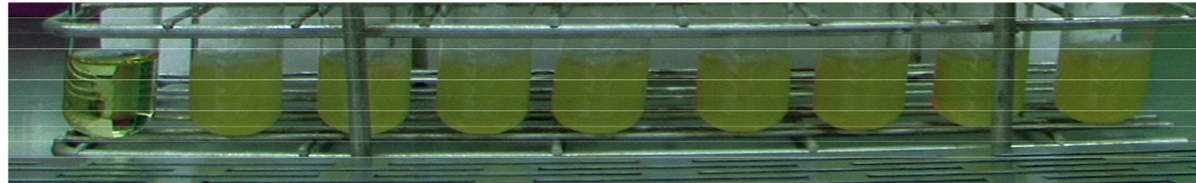

G

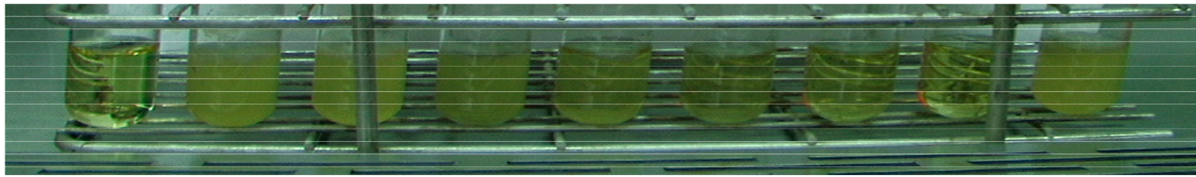

H

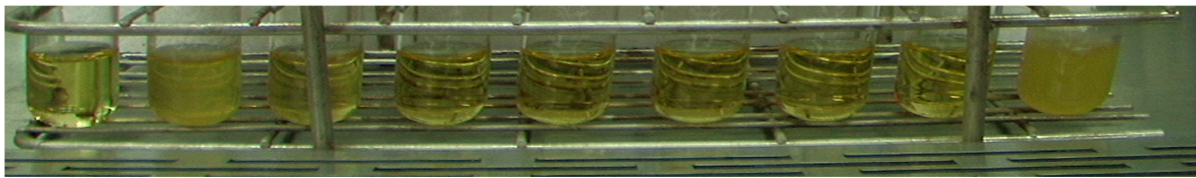

Figure 5. Study of the concentration, size, and MexAB-OprM dependent inhibitory effects of antibiotic nanocarriers (AgMUNH-Oflx NPs) on the growth of $(\mathrm{A}-\mathrm{D}) \mathrm{WT}$ and $(\mathrm{E}-\mathrm{H}) \triangle \mathrm{ABM}$ cells. (A-D) Images of the modified LB medium cultured (a) without cells (blank control) and with WT cells containing $(\mathrm{b}-\mathrm{i}) 0,0.2,0.4,0.6,0.8,1.08,1.62,2.16 \mu \mathrm{M}(\mathrm{A})$ unconjugated free Oflx alone and $(\mathrm{b}-\mathrm{h}) 0.2,0.4,0.6,0.8,1.08,1.62,2.16 \mu \mathrm{M} \mathrm{Oflx}$ conjugated with Ag NPs of (B) $2.4 \pm 0.7$, (C) $13.0 \pm 3.1$, and (D) $92.6 \pm 4.4 \mathrm{~nm}$ in diameter, respectively. (E-H) Images of the modified LB medium cultured $(\mathrm{j})$ without cells (blank control) and with $\triangle \mathrm{ABM}$ cells containing $(\mathrm{k}-\mathrm{r}) 0,0.02,0.04,0.06,0.08,0.11,0.14$, and $0.27 \mu \mathrm{M}(\mathrm{E})$ unconjugated free Oflx alone and (k-r) 0.02, 0.04, 0.06, 0.08, 0.11, 0.14, and 0.27 $\mu \mathrm{M}$ Oflx conjugated with the Ag NPs of (F) 2.4 $\pm 0.7,(\mathrm{G}) 13.0 \pm$ 3.1, and $(\mathrm{H}) 92.6 \pm 4.4 \mathrm{~nm}$ in diameter, respectively. The concentrations of Oflx conjugated onto the NPs are determined based on their conjugation ratios in Table 1. The concentration of $\mathrm{AgMUNH}_{2} \mathrm{NPs}$ in (i) of $(\mathrm{B}-\mathrm{D})$ and $(\mathrm{r})$ of $(\mathrm{F}-\mathrm{H})$ contain the same concentration of NPs as that in (h) and (q) for each type of NP in (B-D) and $(\mathrm{F}-\mathrm{H})$ but without Oflx (control experiments to study the effects of $\mathrm{AgMUNH}_{2} \mathrm{NPs}$ ).

Figure 5E-H: r) for the $2.4 \pm 0.7,13.0 \pm 3.1$, or $92.6 \pm 4.4 \mathrm{~nm}$ NPs, respectively.
We sampled the cell culture suspension every $6 \mathrm{~h}$ and quantitatively determined the cell concentration by measuring their $\mathrm{OD}_{600 \mathrm{~nm}}$ (optical density at $600 \mathrm{~nm}$ ). For the cell 
suspensions with nanocarriers or NPs, we subtracted the $\mathrm{OD}_{600}$ $\mathrm{nm}$ of the nanocarriers or NPs in the medium (in the absence of the cells) from the $\mathrm{OD}_{600 \mathrm{~nm}}$ of the cell suspension with the nanocarriers or NPs to determine the cell concentration, respectively. We plotted the $\mathrm{OD}_{600 \mathrm{~nm}}$ of the cell suspension over time and determined $17 \mathrm{~h}$ to be the duration that is needed for the cell grown in the medium alone (control) to reach confluence and for the cells grown in the medium with Oflx, drug nanocarriers or NPs to reach equilibrium. We then plotted the $\mathrm{OD}_{600 \mathrm{~nm}}$ of the cell suspension at $17 \mathrm{~h}$ versus the concentration of Oflx alone or Oflx conjugated with the given sized drug nanocarriers to determine the MIC of Oflx and Oflx nanocarriers for each cell strain.

Plots of the $\mathrm{OD}_{600 \mathrm{~nm}}$ of the cell suspension cultured over 17 $\mathrm{h}$ versus the concentration of Oflx alone or Oflx conjugated with the given sized drug nanocarriers in Figure 6 show that the inhibitory effects of Oflx highly depend on the dose of Oflx, the sizes of the nanocarriers, and the cellular expression of MexABOprM, as described below.

Control experiments in Figure $6(\mathrm{a}-\mathrm{c})$ show that the $\mathrm{OD}_{600}$ $\mathrm{nm}$ of the cell suspension incubated with each of three different sized $\mathrm{AgMUNH}_{2}$ NPs (absence of Oflx, $2.4 \pm 0.7,13.0 \pm 3.1$, or $92.6 \pm 4.4 \mathrm{~nm}$ ), which has the same concentration of NPs as those of the highest concentration of the given sized nanocarriers, are nearly the same as those cultured in the medium alone. This result indicates that the $\mathrm{AgMUNH}_{2} \mathrm{NPs}$ at the given concentration do not create significant inhibitory effects on the growth of WT and $\triangle \mathrm{ABM}$ cells.

In contrast, the $\mathrm{OD}_{600 \mathrm{~nm}}$ of the cell suspension incubated with Oflx alone shows a high dose dependent inhibitory effect of Oflx on the growth of WT and $\triangle \mathrm{ABM}$ cells (Figure 6A,B: d). As the Oflx concentration increases, the $O_{600 \mathrm{~nm}}$ of the cell suspension (the number of the cells) decreases. By fitting the plots, we found that the growth of WT and $\triangle \mathrm{ABM}$ cells was reduced to half at Oflx concentrations of $0.59 \pm 0.16$ and 0.096 $\pm 0.021 \mu \mathrm{M}$ (Figure 6A,B: d), respectively. The results show that the inhibitory effects are highly dependent on the expression of MexAB-OprM. Here, we define the MIC of Oflx as the concentration of Oflx needed to reduce the growth of the cells by half. The MIC of Oflx for WT (normal expression of MexAB-OprM) is about 6 times higher than that for $\triangle \mathrm{ABM}$ (deletion of MexAB-OprM), suggesting that MexAB-OprM extrudes Oflx out of WT cells. Thus, a higher concentration of Oflx is needed to eradicate the WT cells than that needed for $\triangle \mathrm{ABM}$ cells. In contrast, $\triangle \mathrm{ABM}$ cells do not possess MexAB-OprM and cannot effectively extrude Oflx out of the cells, which leads to a higher accumulation of Oflx inside the $\triangle \mathrm{ABM}$ cells than that in WT cells. Thus, a lower Oflx concentration is needed to eradicate $\triangle \mathrm{ABM}$ cells compared to that for WT cells, which agrees with previous reports. ${ }^{55}$

Plots of $\mathrm{OD}_{600 \mathrm{~nm}}$ of the cell suspension cultured with drug nanocarriers versus the concentration of Oflx conjugated with each given sized $\mathrm{AgMUNH}_{2} \mathrm{NPs}(2.4 \pm 0.7,13.0 \pm 3.1$, or 92.6 $\pm 4.4 \mathrm{~nm}$ ) also show high dose and MexAB-OprM dependent inhibitory effects on the growth of WT and $\triangle \mathrm{ABM}$ cells (Figure 6A,B: e-g). This result suggests that MexAB-OprM can extrude the drug nanocarriers out of the WT cells, which reduces the amount of intracellular Oflx nanocarriers in WT cells and leads to a higher MIC for WT cells than that for $\triangle \mathrm{ABM}$ cells.

Interestingly, the $\mathrm{OD}_{600 \mathrm{~nm}}$ of the cell suspension incubated with the $2.4 \pm 0.7 \mathrm{~nm}$ drug nanocarriers with a conjugation ratio of $8.6 \times 10^{2}$ Oflx molecules/NP decrease with Oflx

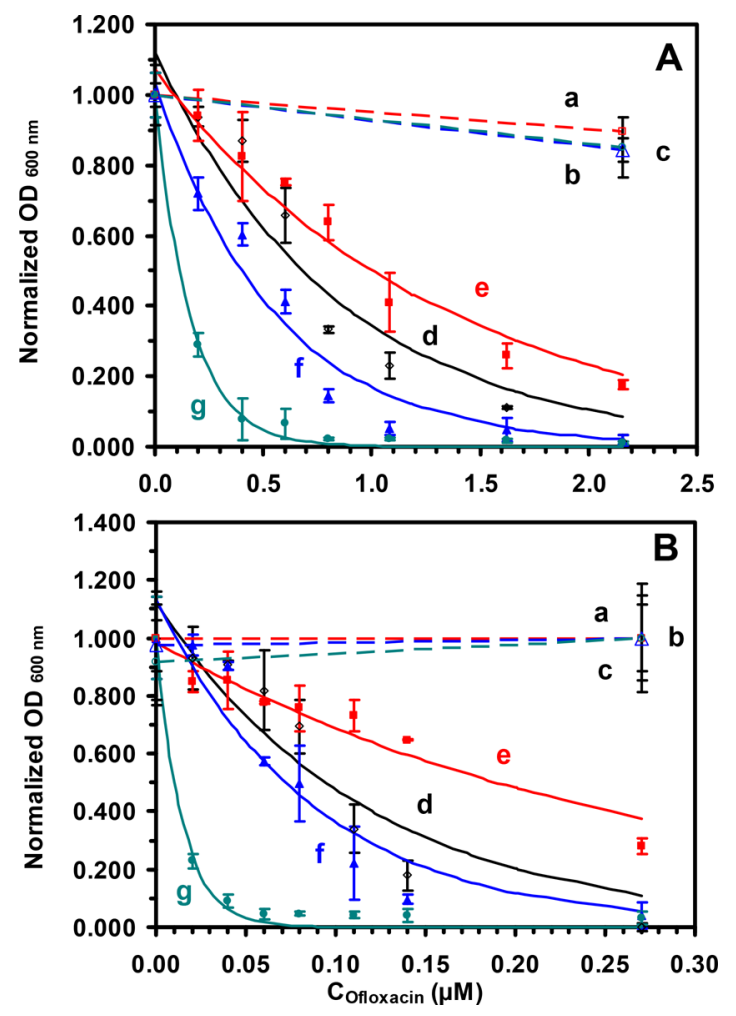

Figure 6. Dose, size, and MexAB-OprM dependent inhibitory effects of antibiotic nanocarriers (AgMUNH-Oflx NPs) against (A) WT and (B) $\triangle \mathrm{ABM}$ cells. Plots of normalized $\mathrm{OD}_{600 \mathrm{~nm}}$ of cells cultured for 17 $\mathrm{h}$ in the modified LB medium containing $(\mathrm{a}-\mathrm{c}) \mathrm{AgMUNH}_{2} \mathrm{NPs}$ (absence of Oflx, control), (d) Oflx alone, and $(\mathrm{e}-\mathrm{g})$ Oflx conjugated with the (e) $2.4 \pm 0.7$, (f) $13.0 \pm 3.1$, and (g) $92.6 \pm 4.4 \mathrm{~nm} \mathrm{Ag} \mathrm{NPs}$, respectively. The concentration of $\mathrm{AgMUNH}_{2} \mathrm{NPs}$ in $(\mathrm{a}-\mathrm{c})$ of $(\mathrm{A})$ and (B) contain the same concentration of NPs as the nanocarriers with the highest Oflx concentrations in $(\mathrm{e}-\mathrm{g})$ for each type of NP in (A) and (B) but without carrying Oflx (control experiments for the study of effects of NPs). The points are experimental data, and a solid line was generated by fitting the experimental data with the equation $y$ $=a \cdot \mathrm{e}^{-b x}$ as followings: (A): (d) $y=1.12 \cdot \mathrm{e}^{-1.18 x}, R^{2}=0.923$; (e) $y=$ $1.07 \cdot \mathrm{e}^{-0.764 x}, R^{2}=0.967$; (f) $y=1.04 \cdot \mathrm{e}^{-1.82 x}, R^{2}=0.964$; (g) $y=0.998$. $\mathrm{e}^{-6.07 x}, R^{2}=0.997$. (B): (d) $y=1.12 \cdot \mathrm{e}^{-8.59 x}, R^{2}=0.892$; (e) $y=0.984$. $\mathrm{e}^{-3.58 x}, R^{2}=0.938$; (f) $y=1.13 \cdot \mathrm{e}^{-11.35 x}, R^{2}=0.920$; (g) $y=0.997$. $\mathrm{e}^{-68.82 x}, R^{2}=0.989$. Concentrations of Oflx $\left(\mathrm{MIC}, \mathrm{IC}_{50}\right)$ for free Oflx and Oflx conjugated on a given sized nanocarrier were determined using the exponential fitting equation at the half of the maximum of the normalized $\mathrm{OD}_{600 \mathrm{~nm}}$ for each curve, respectively.

concentration less rapidly than those of free Oflx and the two other larger nanocarriers (Figure 6A,B: e), showing MICs of $1.00 \pm 0.07$ and $0.19 \pm 0.05 \mu \mathrm{M}$ Oflx for the WT and $\triangle \mathrm{ABM}$ cells, which is the highest among the nanocarriers and free Oflx (Table 2).

Notably, the MICs of the $13.0 \pm 3.1 \mathrm{~nm}$ drug nanocarriers with a conjugation ratio of $9.6 \times 10^{3}$ Oflx molecules/NP are $0.40 \pm 0.06$ and $0.073 \pm 0.012 \mu \mathrm{M}$ for the WT and $\Delta \mathrm{ABM}$ cells, respectively (Figure 6A,B: f), which is lower than the MICs of free Oflx and the $2.4 \pm 0.7 \mathrm{~nm}$ drug nanocarriers. Furthermore, the MICs of the $92.6 \pm 4.4 \mathrm{~nm}$ drug nanocarriers with a conjugation ratio of $6.5 \times 10^{5} \mathrm{Oflx}$ molecules/NP are $0.11 \pm 0.01$ and $0.010 \pm 0.001 \mu \mathrm{M}$ for the WT and $\Delta \mathrm{ABM}$ cells, respectively (Figure 6A,B: g), showing the lowest MIC and the highest inhibitory effects among the nanocarriers and free Oflx. The results show that the inhibitory effects of Oflx are highly dependent on the dose of Oflx, the size of the 
Table 2. Dependence of the MIC of Oflx on the Sizes of the Nanocarriers and Expression of MexAB-OprM for Two Strains of $P$. aeruginosa (WT and $\triangle \mathrm{ABM}$ )

\begin{tabular}{lcc} 
& \multicolumn{2}{c}{$\mathrm{MIC}_{50}$ of Oflx $(\mu \mathrm{M})^{a}$} \\
\cline { 2 - 3 } \multicolumn{1}{c}{ samples } & WT & $\Delta \mathrm{ABM}$ \\
free Oflx alone & $0.59 \pm 0.16$ & $0.096 \pm 0.021$ \\
nanocarriers $(2.4 \pm 0.7 \mathrm{~nm})$ & $1.00 \pm 0.07$ & $0.19 \pm 0.05$ \\
nanocarriers $(13.0 \pm 3.1 \mathrm{~nm})$ & $0.40 \pm 0.06$ & $0.073 \pm 0.012$ \\
nanocarriers $(92.6 \pm 4.4 \mathrm{~nm})$ & $0.11 \pm 0.01$ & $0.010 \pm 0.001$
\end{tabular}

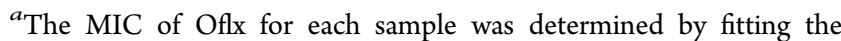
experimental data with the exponential decay equation $\left(y=a \cdot e^{-b x}\right.$, inhibitory effects upon exponential cell growth) to determine the parameters $(a$ and $b$ ) of a fitting equation with a regression. The equation was then used to determine the concentration of Oflx at which the cell growth was inhibited to half of the cell growth of the blank control experiment, as described in the caption of Figure 6.

nanocarrier, and the cellular expression of MexAB-OprM. For the same amount of Oflx against WT and $\triangle \mathrm{ABM}$ cells, the Oflx molecules carried and delivered by the largest NPs $(92.6 \pm 4.4$ $\mathrm{nm})$ are the most potent, followed by the $13.0 \pm 3.1 \mathrm{~nm}$ nanocarriers, free Oflx, and the $2.4 \pm 0.7 \mathrm{~nm}$ nanocarriers (Table 2).

For $\triangle \mathrm{ABM}$ cells (absence of MexAB-OprM), the MICs of Oflx conjugated on the $13.0 \pm 3.1$ and $92.6 \pm 4.4 \mathrm{~nm}$ nanocarriers are 2.6 and 19 times lower than that of Oflx conjugated on the smallest nanocarriers $(2.4 \pm 0.7 \mathrm{~nm})$. In other words, the same amount of Oflx is the most potent when it is delivered into the cells using the largest nanocarriers (92.6 $\pm 4.4 \mathrm{~nm}$ ) and vice versa, suggesting that densely packed Oflx on larger nanocarriers could offer a higher binding affinity with the target (multivalent effect) and a higher local drug dose for binding with the target compared to those of Oflx molecules conjugated on the smaller nanocarriers. Interestingly, the MIC of free Oflx against the $\triangle \mathrm{ABM}$ cells is only half of the MIC of Oflx on the $2.4 \pm 0.7 \mathrm{~nm}$ nanocarriers, but it is nearly the same as that of Oflx on the $13.0 \pm 3.1 \mathrm{~nm}$ nanocarriers and almost 10 times higher than that of Oflx on the $92.6 \pm 4.4 \mathrm{~nm}$ nanocarriers. In other words, the inhibitory effects of the drug nanocarriers depend on their sizes, but they are not linearly proportional to their sizes, which suggests that the distribution of the same amount of the drug throughout the cells (pharmacodynamics) versus the localization of the same drug dose on individual nanocarriers (high affinity) could play roles that trade off with regard to their inhibitory effects. Free Oflx and smaller nanocarriers diffuse faster and the Oflx could be better distributed inside the cells than Oflx on the larger nanocarriers. In contrast, the larger nanocarriers offer a higher local drug dose and higher affinity with the target than the smaller nanocarriers. The combination of both factors creates the optimal susceptibility of the nanocarriers against the cells. This result suggests that a critical size of the nanocarriers could be needed to generate optimal potency against the bacterial cells.

For WT cells, the MICs of Oflx attached onto the $13.0 \pm 3.1$ and $92.6 \pm 4.4 \mathrm{~nm}$ NPs are 2.5 and 9.1 times lower than that of Oflx on the smallest nanocarriers $(2.4 \pm 0.7 \mathrm{~nm})$, respectively. Similar to those observed in using $\triangle \mathrm{ABM}$ cells, the same amount of Oflx is the most potent when it is delivered into the WT cells using the largest nanocarriers $(92.6 \pm 4.4 \mathrm{~nm})$ and vice versa, further suggesting that densely packed Oflx on the larger nanocarriers could offer a higher local concentration and higher binding affinity with the target than those when they are conjugated on the smaller NPs. The inhibitory effects of the drug nanocarriers depend on their sizes, but they are not linearly proportional to their sizes. Interestingly, MexAB-OprM affects the susceptibility of drug nanocarriers in a sizedependent fashion. For example, the ratios of the MIC of WT to $\triangle \mathrm{ABM}$ cells for free Oflx and Oflx conjugated on the 2.4 $\pm 0.7,13.0 \pm 3.1$, and $92.6 \pm 4.4 \mathrm{~nm}$ drug nanocarriers are 6.1, 5.3, 5.5, and 11, respectively, as shown in Figure 6 and Table 2.

Notably, for WT cells, the net gain in the amount of accumulated intracellular nanocarriers is determined by subtracting the amount of nanocarriers extruded out of the cells by MexAB-OprM from the amount of nanocarriers that entered the cells. Note that $\triangle \mathrm{ABM}$ cells were constructed by the deletion of mexAB-oprM in WT cells. Thus, the amount of the nanocarriers that entered the $\triangle \mathrm{ABM}$ cells should be the same as those entered the WT cells. If the extrusion of nanocarriers by MexAB-OprM was size-independent, then the ratio of the MICs of WT to $\triangle \mathrm{ABM}$ cells for each sized nanocarrier should be the same, respectively. However, they were not. The MIC of the largest nanocarriers $(92.6 \pm 4.4 \mathrm{~nm})$ against $\triangle \mathrm{ABM}$ is 19 times lower than that of the smallest nanocarriers $(2.4 \pm 0.7 \mathrm{~nm})$, whereas the MIC of the largest nanocarriers $(92.6 \pm 4.4 \mathrm{~nm})$ against WT is 9 times lower than that of the smallest nanocarrier $(2.4 \pm 0.7 \mathrm{~nm})$. A plausible explanation for this finding is the size-dependent efflux function of MexAB-OprM, and MexAB-OprM could extrude Oflx molecules on the largest nanocarriers out of the WT cells, which could affect the MIC of the largest nanocarriers the most. For example, when the cell extrudes a largest nanocarrier, it can reduce the intracellular Oflx 756 times more than extrusion of a smallest carrier. Because the inhibitory effects of the largest nanocarriers $(92.6 \pm 4.4 \mathrm{~nm})$ are much higher than the two other sized nanocarriers and free Oflx, we still observed the lowest MIC of the largest nanocarriers against the WT cells, despite its extrusion by MexAB-OprM affecting the accumulation of intracellular Oflx the most. These interesting findings further demonstrate that the combination of several factors (multivalence, pharmacodynamics, and pharmacokinetics, e.g., distribution and efflux of Oflx and Oflx nanocarriers) affects the inhibitory effects of Oflx against the cells. This study demonstrates the possibility of designing antibiotic nanocarriers that could potentially generate the most potent effect against highly infectious bacterial cells, such as $P$. aeruginosa.

\section{SUMMARY}

We have synthesized and characterized three different sized antibiotic nanocarriers (AgMUNH-Oflx NPs) by functionalizing three different sized Ag NPs $(2.4 \pm 0.7,13.0 \pm 3.1$, and 92.6 $\pm 4.4 \mathrm{~nm}$ ) with a monolayer of AUT to prepare $\mathrm{AgMUNH}_{2}$ NPs, followed by covalently linking them with antibiotic (Oflx) molecules. We successfully developed a modified LB medium to culture $P$. aeruginosa (WT and $\triangle \mathrm{ABM}$ ) that allows the nanocarriers (AgMUNH-Oflx NPs) and $\mathrm{AgMUNH}_{2} \mathrm{NPs}_{\text {at }}$ the desired concentration to be stable (non-aggregated) throughout the duration of the cell culture experiment. We studied the dependence of the inhibitory effects of free Oflx and Oflx covalently attached onto the surface of nanocarriers on the dose of Oflx, the sizes of the nanocarriers, and the cellular expression of MexAB-OprM. We found that the inhibitory effects of Oflx highly depend on the dose of Oflx, the size of the nanocarrier, and the cellular expression of MexAB-OprM. Interestingly, the largest nanocarriers $(92.6 \pm 4.4 \mathrm{~nm})$ have the lowest MICs of 
$0.11 \pm 0.01$ and $0.010 \pm 0.001 \mu \mathrm{M}$ Oflx against WT and $\triangle \mathrm{ABM}$ cells, following by the $13.0 \pm 3.1 \mathrm{~nm}$ nanocarriers and free Oflx, whereas the smallest nanocarriers $(2.4 \pm 0.7 \mathrm{~nm})$ have the highest MICs of $1.00 \pm 0.07$ and $0.19 \pm 0.05 \mu \mathrm{M}$ Olfx against WT and $\triangle \mathrm{ABM}$ cells, respectively. The results show that the largest nanocarriers exhibit the highest bactericidal effects, whereas the smallest nanocarriers show the lowest bactericidal effects, demonstrating that the same amount of Oflx creates a higher bactericidal effect when they are carried and delivered by larger NPs. These findings suggest that the close-packed Oflx molecules on the NPs (multivalence) could enhance their binding affinity with the target and offer a higher payload to increase the local drug dose and potency. Notably, the MIC of the largest nanocarriers $(92.6 \pm 4.4 \mathrm{~nm})$ for $\triangle \mathrm{ABM}$ is 19 times lower than that for the smallest nanocarriers $(2.4 \pm$ $0.7 \mathrm{~nm}$ ), whereas the MIC of the largest nanocarriers (92.6 \pm $4.4 \mathrm{~nm}$ ) for WT is 9 times lower than that of the smallest nanocarriers $(2.4 \pm 0.7 \mathrm{~nm})$. The results suggest that MexABOprM can effectively extrude such large nanocarriers out of WT cells and that the extrusion of the larger nanocarriers can affect the inhibitory effect of Oflx more significantly than the smaller nanocarriers due to the larger payload of Oflx on the larger nanocarriers. In other words, MexAB-OprM could be more efficient at protecting bacteria from larger nanocarriers than small nanocarriers. Interestingly, although the inhibitory effects of the drug nanocarriers depend on their sizes, they are not linearly proportional to their sizes, which suggests that the inhibitory effects of Oflx depend not only on multivalent local targeting effects but also on its intracellular distribution (pharmacodynamics) and extrusion by the transporter. Thus, an optimal size of the nanocarriers would be needed to generate optimal inhibitory effects. These interesting findings further demonstrate the possibility of designing antibiotic nanocarriers that could potentially evade MDR and generate the most potent effect against highly infectious bacterial cells, such as $P$. aeruginosa.

\section{MATERIALS AND METHODS}

Reagents and Supplies. We purchased silver perchlorate monohydrate (99\%, Alfa Aesar), sodium citrate dihydrate (99\%, Sigma), sodium borohydride (98\%, Sigma), hydrogen peroxide (30\%, Sigma), polyvinylpyrrolidone (PVP, Sigma), 2-mercaptoethanol (99\%, Sigma), 11-amino-1-undecanethiol hydrochloride (AUT, 99\%, Sigma), 1-ethyl-3-[3-(dimethylamino)propyl]-carbodiimide hydrochloride (EDC, 99\%, Pierce), $\mathrm{N}$ hydroxysulfosuccinimide (sulfo-NHS, $98.5 \%$, Pierce), ofloxacin ( $\geq 98 \%$, Oflx, Enzo), L-broth (LB) powder (Sigma), and the LIVE/DEAD BacLight viability and counting assay (Invitrogen) and used them as received. We used nanopure deionized (DI) water (18 M $\Omega$ water, Barnstead) to prepare commonly used standard LB medium ( $1 \%$ tryptone, $0.5 \%$ yeast extract, and $0.5 \% \mathrm{NaCl}$ in $\mathrm{DI}$ water, $\mathrm{pH}=7.2)$ and our modified $\mathrm{LB}$ medium ( $1 \%$ tryptone, $0.5 \%$ yeast extract, and $0.1 \% \mathrm{NaCl}$ in DI water, $\mathrm{pH}=7.2)$

Cell Lines, Cell Culture Medium, Cell Culture, and Characterization. Three strains of Gram-negative bacterial cells ( $P$. aeruginosa), WT (PA04290, normal expression of MexAB-OprM), nalB-1 (overexpression mutant of MexABOprM), and $\triangle \mathrm{ABM}$ (deletion of MexAB-OprM), were generously provided by Dr. Hiroshi Yoneyama and used for this study. ${ }^{51,56}$ We first precultured the cells in commonly used standard LB medium for $12 \mathrm{~h}$. We then cultured the cells using either standard LB medium or modified LB medium in a shaker
(MaxQ 5000, $200 \mathrm{rpm}, 37^{\circ} \mathrm{C}$ ) for another $8 \mathrm{~h}$. We followed the growth of the cells in each respective medium over time and characterized the cell growth curves by measuring the $\mathrm{OD}_{600 \mathrm{~nm}}$ of the cell suspensions in the medium every 30 min over $8 \mathrm{~h}$ of cell culture. We studied the viability of the cultured cells by the end of culture at single cell resolution using LIVE/DEAD BacLight viability and counting assay. ${ }^{57}$ The cells in the medium were imaged in a microchamber using dark-field optical microscopy and epifluorescence microscopy. $33,36,40,41,50$ The green fluorescence cells (peak wavelength of the fluorescence spectra of SYTO9, $\lambda_{\max }=520 \mathrm{~nm}$ ) and red fluorescence cells (peak wavelength of the fluorescence spectra of propidium iodide, $\lambda_{\max }=610 \mathrm{~nm}$ ) were used to determine live and dead cells, respectively. ${ }^{57}$

By the end of the cell culture, we harvested the cells using centrifugation (Beckman JA-14, $7500 \mathrm{rpm}$ ) and rinsed them with PBS buffer $(0.5 \mathrm{mM}$ phosphate buffer, $1.5 \mathrm{mM} \mathrm{NaCl}, \mathrm{pH}$ 7.0) three times via centrifugation. We then suspended the cells in PBS buffer and adjusted the cell suspension concentration to $\mathrm{OD}_{600 \mathrm{~nm}}=0.1 .^{36,40,41,50,52,53} \mathrm{We}$ characterized the efflux function of the MexAB-OprM membrane transporter of live cells cultured in each medium by continuously measuring the fluorescence intensity of the cell suspension $\left(\mathrm{OD}_{600 \mathrm{~nm}}=0.1\right)$ containing $10 \mu \mathrm{M} \mathrm{EtBr}$ in real time ( $3 \mathrm{~s}$ time interval) for $2 \mathrm{~h}$ using a fluorescence spectrometer (PerkinElmer LS50B) with the excitation and emission wavelengths at 465 and $600 \mathrm{~nm}$, respectively. ${ }^{50,52,53}$

Synthesis and Characterization of Ag NPs. We had synthesized, purified, and characterized three different sized $\mathrm{Ag}$ NPs with diameters of $2.4 \pm 0.7,13.0 \pm 3.1$, and $92.6 \pm 4.4 \mathrm{~nm}$, as we reported previously. ${ }^{32,37,38,46-48,58}$ Briefly, we synthesized $\mathrm{Ag}$ NPs with a diameter of $2.4 \pm 0.7 \mathrm{~nm}$ by adding $\mathrm{NaBH}_{4}(150$ $\mu \mathrm{L}, 100 \mathrm{mM})$ into a stirring mixture $(42.3 \mathrm{~mL})$ of silver nitrate $(0.11 \mathrm{mM})$, sodium citrate $(1.91 \mathrm{mM})$, PVP $(0.052 \mathrm{mM})$, and hydrogen peroxide $(25.0 \mathrm{mM})$ that was freshly prepared using nanopure water. ${ }^{38}$ We stirred the solution at room temperature for another $3 \mathrm{~h}$ and filtered the solution using $0.2 \mu \mathrm{m}$ membrane filters. We prepared Ag NPs with a diameter of 13.0 $\pm 3.1 \mathrm{~nm}$ by rapidly adding ice-cold $\mathrm{AgClO}_{4}(2.5 \mathrm{~mL}$ of 10 $\mathrm{mM})$ into a stirring ice-cold mixture $(247.5 \mathrm{~mL})$ of sodium citrate $(3 \mathrm{mM})$ and $\mathrm{NaBH}_{4}(10 \mathrm{mM}) .^{34,39}$ We stirred the solution at room temperature for $4 \mathrm{~h}$ and filtered it using a 0.2 $\mu \mathrm{m}$ filter. We synthesized $92.6 \pm 4.4 \mathrm{~nm} \mathrm{Ag} \mathrm{NPs} \mathrm{by} \mathrm{adding}$ sodium citrate $(10 \mathrm{~mL}, 34 \mathrm{mM})$ into a refluxing $\left(100{ }^{\circ} \mathrm{C}\right)$ aqueous solution of $3.98 \mathrm{mM} \mathrm{AgNO}_{3}(500 \mathrm{~mL}) .{ }^{32,59}$ We stirred the mixture at $325 \mathrm{rpm}$ for $35 \mathrm{~min}$ and cooled the solution to room temperature. We then added additional $2.5 \mathrm{mM}$ sodium citrate as a stabilizer into the solution and filtered the solution using a $0.2 \mu \mathrm{m}$ filter.

We purified each NP solution by thoroughly washing the NPs three times with DI water using centrifugation immediately after the synthesis. We characterized the NP concentration, LSPR images and spectra, and sizes of single NPs using UV-vis spectroscopy (Hitachi U-2010), dark-field optical microscopy and spectroscopy (DFOMS), highresolution transmission electron microscopy (HRTEM) (JEOL, JEM-2100F), and dynamic light scattering (DLS) (Nicomp 380ZLS particle sizing system), respectively. We have fully described our DFOMS approach in our previous studies. . $^{3,34,36-41,44,52,60,61}$ In this study, the DFOMS system is equipped with a dark-field optical microscope with a darkfield condenser (oil 1.43-1.20, Nikon) and a 100× objective (Nikon Plan fluor $100 \times$ oil, iris, SL. N.A. 0.5-1.3, W.D. 0.20 
$\mathrm{mm}$ ), a CCD camera (Micromax, Roper Scientific), and a multispectral imaging system (Nuance, CRI). ${ }^{38,60}$

Synthesis and Characterization of Drug Nanocarriers (AgMUNH-Oflx NPs). We added AUT (1 mL, $100 \mathrm{mM}$, in ethanol) into the freshly prepared Ag NPs ( $100 \mathrm{~mL}, 50 \mathrm{nM}, 3.3$ $\mathrm{nM}$, and $30 \mathrm{pM})$ of three different sizes $(2.4 \pm 0.7,13.0 \pm 3.1$ and $92.6 \pm 4.4 \mathrm{~nm}$ ), respectively. We stirred the mixtures for 24 $h$ to attach AUT onto the surface of the NPs via the interaction of thiol groups with the NPs to prepare functional $\mathrm{AgMUNH}_{2}$ NPs (Figure 2). We washed the $\mathrm{AgMUNH}_{2} \mathrm{NPs}$ thoroughly three times with nanopure water to remove excess AUT using centrifugation (Beckman Optima L90k, $4{ }^{\circ} \mathrm{C}$ ). After each washing and resuspension step, we immediately characterized the concentrations, optical properties, and sizes of each $\mathrm{AgMUNH}_{2} \mathrm{NP}$ solution using UV-vis spectroscopy, DFOMS, and DLS, respectively. Note that the $\mathrm{AgMUNH}_{2}$ NPs were suspended in DI water for storage and only suspended in the respective buffer immediately before the experiment.

We suspended half of the purified $\mathrm{AgMUNH}_{2} \mathrm{NP}$ solution $(50 \mathrm{~mL})$ in PBS buffer ( $\mathrm{pH} 7.0)$ immediately before control experiments. We suspended the other half of the $\mathrm{AgMUNH}_{2}$ $\mathrm{NP}$ solution (50 mL) in MES buffer (50 mM, pH 5.0) immediately before conjugating these NPs with Oflx. We conjugated the amine groups of each size of $\mathrm{AgMUNH}_{2} \mathrm{NPs}$ $(50 \mathrm{~mL})$ with the carboxyl group of Oflx via peptide bonds using a two-step method with EDC and sulfo-NHS as mediators (Figure 2), as described in the following. We first dissolved Oflx in $0.5 \mathrm{M} \mathrm{HCl}(1 \mathrm{~mL})$ and then diluted it using MES buffer ( $\mathrm{pH} 5.0)$. We added EDC $(100 \mu \mathrm{L}, 100 \mathrm{mM})$ and sulfo-NHS (100 $\mu \mathrm{L}, 500 \mathrm{mM})$ into the Oflx solution $(3 \mathrm{~mL}, 50$ $\mathrm{mM}$ ) and stirred it at room temperature for $40 \mathrm{~min}$ to form Oflx-sulfo-NHS esters. We added 2-mercaptoethanol to quench the excess EDC. We added the Oflx-sulfo-NHS esters to the $\mathrm{AgMUNH}_{2} \mathrm{NPs}$ in MES buffer ( $\mathrm{pH}$ 5.0) and mixed the solution using a rotary shaker at room temperature for $3 \mathrm{~h}$ to synthesize the AgMUNH-Oflx NPs (nanocarriers).

We purified the drug nanocarriers (AgMUNH-Oflx NPs) by washing them with DI water three times and stored them at 4 ${ }^{\circ} \mathrm{C}$ for future use. After each washing step, we immediately characterized the concentrations, optical properties, and sizes of the $\mathrm{AgMUNH}_{2} \mathrm{NPs}_{\mathrm{N}}$ using UV-vis spectroscopy, DFOMS, and $\mathrm{DLS}$, respectively. We measured the UV-vis absorbance spectra of various concentrations of nanocarriers (AgMUNHOflx NPs) and plotted the peak absorbance of the nanocarriers versus their concentrations to construct a calibration curve and determine their molar absorptivity.

We measured the UV-vis absorbance spectra of various concentrations of Oflx alone (absence of NPs) in solution and plotted the peak absorbance at $288 \mathrm{~nm}$ versus Oflx concentration to construct a calibration curve and determine its molar absorptivity $\left(\varepsilon_{288 \mathrm{~nm}}=7.8 \times 10^{3} \mathrm{M}^{-1} \mathrm{~cm}^{-1}\right.$ and $\varepsilon_{330 \mathrm{~nm}}$ $\left.=2.4 \times 10^{3} \mathrm{M}^{-1} \mathrm{~cm}^{-1}\right)$. We subtracted the UV-vis absorption spectrum of the $\mathrm{AgMUNH}_{2} \mathrm{NPs}$ from that of AgMUNH-Oflx NPs of the same size and concentration to obtain the UV-vis absorption spectrum of Oflx conjugated with the $\mathrm{AgMUNH}_{2}$ NPs, and we used the molar absorptivity of Oflx to determine its concentration. We also determined the NP concentration based on the peak absorbance of the plasmonic absorption spectra of the NPs. By dividing the concentration of Oflx with concentration of NPs in the same AgMUNH-Oflx NP solution using UV-vis absorption spectroscopy, we determined the conjugation ratio of Oflx molecules to NPs for each size of drug nanocarrier.

Stability of Drug Nanocarriers (AgMUNH-Oflx NPs) in Cell Culture Medium. We characterized the stability (nonaggregation) of AgMUNH-Oflx NPs in the commonly used standard LB medium ( $1 \%$ tryptone, $0.5 \%$ yeast extract, and $0.5 \% \mathrm{NaCl}$ in $\mathrm{DI}$ water, $\mathrm{pH}=7.2$ ) and the modified medium ( $1 \%$ tryptone, $0.5 \%$ yeast extract, and $0.1 \% \mathrm{NaCl}$ in $\mathrm{DI}$ water, $\mathrm{pH}=7.2$ ) over $24 \mathrm{~h}$ using UV-vis absorption spectroscopy. We found that the nanocarriers with Ag NP diameters of $2.4 \pm$ $0.7,13.0 \pm 3.1$, and $92.6 \pm 4.4 \mathrm{~nm}$ at the desired concentration (6.0 nM, $0.8 \mathrm{nM}$ and $7 \mathrm{pM}$ ) were stable (non-aggregated) in the modified medium over $24 \mathrm{~h}$, but they are unstable (aggregated) in the standard medium, respectively.

Inhibitory Effects of Drug Nanocarriers (AgMUNHOflx NPs). We pre-cultured the cells (WT or $\triangle \mathrm{ABM}$ ) in the standard LB medium overnight. We then cultured the cells in the modified LB medium ( $4 \mathrm{~mL}$ ) containing a dilution series of Oflx alone, a given sized drug nanocarrier (AgMUNH-Oflx $\mathrm{NPs}$ ), and $\mathrm{AgMUNH}_{2} \mathrm{NPs}$ (control experiments) by inoculating $10^{4}$ pre-cultured cells into the medium and vigorously shaking the solution $\left(200 \mathrm{rpm}, 37^{\circ} \mathrm{C}\right)$ over $18 \mathrm{~h}$.

The dilution series contains $0,0.20,0.40,0.60,0.80,1.08$, 1.62 , and $2.16 \mu \mathrm{M}$ free Oflx or Oflx conjugated with the NPs (AgMUNH-Oflx NPs) for WT cells, which is correlated with the concentration of the nanocarriers (NP concentration) as follows: (i) $0.23,0.463,0.695,0.917,1.25,1.88$, and $2.50 \mathrm{nM}$ for the $2.4 \pm 0.7 \mathrm{~nm} \mathrm{NPs}$ with a conjugation ratio of $8.6 \times 10^{2}$ Oflx molecules per NP; (ii) $2.12 \times 10^{-2}, 4.24 \times 10^{-2}, 6.36 \times$ $10^{-2}, 8.48 \times 10^{-2}, 0.114,0.172$, and $0.229 \mathrm{nM}$ for the $13.0 \pm$ $3.1 \mathrm{~nm} \mathrm{NPs}$ with a conjugation ratio of $9.4 \times 10^{3}$ Oflx molecules per NP; and (iii) 0.309, 0.618, 0.926, 1.24, 1.67, 2.50, and $3.34 \mathrm{pM}$ for the $92.6 \pm 4.4 \mathrm{~nm}$ NPs with a conjugation ratio of $6.5 \times 10^{5} \mathrm{Oflx}$ molecules per NP, respectively. The control experiments include the modified LB medium alone (absence of cells) and WT cells cultured under the same conditions and at the same time in the medium containing 2.50 $\mathrm{nM}, 0.229 \mathrm{nM}$, or $3.34 \mathrm{pM}$ AgMUNH$_{2} \mathrm{NPs}_{\text {(in the absence of }}$ Oflx) for the $2.4 \pm 0.7,13.0 \pm 3.1$, or $92.6 \pm 4.4 \mathrm{~nm} \mathrm{Ag} \mathrm{NPs,}$ respectively.

The dilution series contains 0, 0.020, 0.040, 0.060, 0.080, $0.11,0.14,0.28 \mu \mathrm{M}$ free Oflx or Oflx conjugated with the NPs (AgMUNH-Oflx NPs) for $\triangle \mathrm{ABM}$ cells, which is correlated with the concentration of the nanocarrier (NP concentration) as follows: (i) $2.32 \times 10^{-2}, 4.63 \times 10^{-2}, 6.95 \times 10^{-2}, 9.27 \times$ $10^{-2}, 0.127,0.162$, and $0.324 \mathrm{nM}$ for the $2.4 \pm 0.7 \mathrm{~nm} \mathrm{NPs}$ with a conjugation ratio of $8.6 \times 10^{2}$ Oflx molecules per NP; (ii) $2.12 \times 10^{-3}, 4.24 \times 10^{-3}, 6.36 \times 10^{-3}, 8.48 \times 10^{-3}, 1.48 \times$ $10^{-2}$, and $2.97 \times 10^{-2} \mathrm{nM}$ for the $13.0 \pm 3.1 \mathrm{~nm}$ NPs with a conjugation ratio of $9.4 \times 10^{3}$ Oflx molecules per NP; and (iii) $3.09 \times 10^{-2}, 6.18 \times 10^{-2}, 9.26 \times 10^{-2}, 0.124,0.170,0.216$, and $0.432 \mathrm{pM}$ for the $92.6 \pm 4.4 \mathrm{~nm}$ NPs with a conjugation ratio of $6.5 \times 10^{5}$ Oflx molecules per NP. The control experiments included the modified LB medium alone (absence of cells) and the $\triangle \mathrm{ABM}$ cells cultured under the same conditions and at the same time in the medium containing $0.324 \mathrm{nM}, 2.97 \times 10^{-2}$ $\mathrm{nM}$, or $0.432 \mathrm{pM} \mathrm{AgMUNH} \mathrm{APs}_{2}$ (in the absence of Oflx) for the $2.4 \pm 0.7,13.0 \pm 3.1$, or $92.6 \pm 4.4 \mathrm{~nm} \mathrm{Ag} \mathrm{NPs}$, respectively.

We sampled the cell culture suspension every $6 \mathrm{~h}$ and quantitatively determined the cell concentration by measuring their $\mathrm{OD}_{600 \mathrm{~nm}}$ in a 96-well plate using a plate reader (BioTek Synergy HT) equipped with an UV-vis absorption spectral 
detector. We plotted the $\mathrm{OD}_{600 \mathrm{~nm}}$ of the cell suspension over time to determine the duration $(17 \mathrm{~h})$ that is needed for the cells to reach confluence. We used the $\mathrm{OD}_{600 \mathrm{~nm}}$ of each cell suspension at $17 \mathrm{~h}$ to determine their inhibitory effects as described in the following.

We normalized the $\mathrm{OD}_{600 \mathrm{~nm}}$ of each cell suspension with the maximum $\mathrm{OD}_{600 \mathrm{~nm}}$ (the cells cultured in medium alone, blank control) among the dilution series of the cell suspensions for each type of sample (e.g., free Oflx and each sized nanocarrier). We then plotted the normalized $\mathrm{OD}_{600 \mathrm{~nm}}$ of the cell suspension versus the concentration of free Oflx (Oflx alone) or the concentration of Oflx attached onto a given sized drug nanocarrier to determine the MIC of Oflx. Each experiment was repeated three times. For each sample, the average of three experimental measurements with a standard deviation of the normalized $\mathrm{OD}_{600 \mathrm{~nm}}$ of each cell suspension (points in Figure 6) was fitted using the exponential decay $\left(y=a \cdot e^{-b x}\right.$, inhibitory effects upon the exponential cell growth) to determine the parameters $(a, b)$ of the equation with the highest possible regression. The equation was then used to determine the MIC (the concentration of Oflx at which the cell growth was inhibited to half of the cell growth of the blank control experiment), as described in the caption of Figure 6. For example, the points in Figure 6 are experimental data, and a solid line is generated by fitting the experimental data with the equation $y=a \cdot \mathrm{e}^{-b x}$ as follows: (A): (d) $y=1.12 \cdot \mathrm{e}^{-1.18 x}, R^{2}=$ 0.923 ; (e) $y=1.07 \cdot \mathrm{e}^{-0.764 x}, R^{2}=0.967$; (f) $y=1.04 \cdot \mathrm{e}^{-1.82 x}, R^{2}=$ 0.964; (g) $y=0.998 \cdot \mathrm{e}^{-6.07 x}, R^{2}=0.997$. (B): (d) $y=1.12 \cdot \mathrm{e}^{-8.59 x}$, $R^{2}=0.892$; (e) $y=0.984 \cdot \mathrm{e}^{-3.58 x}, R^{2}=0.938$; (f) $y=1.13$. $\mathrm{e}^{-11.35 x}, R^{2}=0.920 ; \quad(\mathrm{g}) y=0.997 \cdot \mathrm{e}^{-68.82 x}, R^{2}=0.989$. Parameters " $a$ " and " $b$ " in the equation for each sample were determined based on the best fit (i.e., the highest regression with the lowest error). Concentrations of Oflx (MIC, $\mathrm{IC}_{50}$ ) for free Oflx and Oflx conjugated with a given sized nanocarrier were determined using the exponential fitting equation at half of the maximum normalized $\mathrm{OD}_{600 \mathrm{~nm}}$ for each curve. As a control experiment, we also plotted the normalized $\mathrm{OD}_{600 \mathrm{~nm}}$ of the cell suspension at $17 \mathrm{~h}$ versus the concentration of

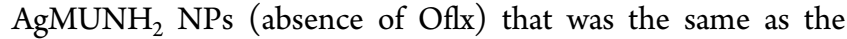
highest concentration of the given nanocarrier for each cell strain.

Data Analysis and Statistics. We characterized the sizes and shapes of Ag NPs using TEM, and we acquired LSPR spectra of single Ag NPs, AgMUNH ${ }_{2}$ NPs, and AgMUNH-Oflx NPs using DFOMS. For each size and each type of the NP, we imaged at least $100 \mathrm{NPs}$ for each measurement, and we repeated each experiment three times. Thus, a minimum of 300 NPs were characterized using TEM and DFOMS. All experiments, including the study of the stability of the NPs in the medium, cell growth curves, and MICs, were repeated three times. We used the average of three measurements with standard deviations for each study as described above.

\section{ASSOCIATED CONTENT}

\section{S Supporting Information}

The Supporting Information is available free of charge on the ACS Publications website at DOI: 10.1021/acsomega.7b01956.

Figure S1: Characterization of growth kinetics of live cells cultured in standard and modified LB medium. Figure S2: Characterization of viability of the cells cultured in standard and modified LB medium using Live/Dead BacLight assay. Figure S3: Characterization of accumulation and efflux kinetics of EtBr for live cells cultured in standard and modified LB medium (PDF)

\section{AUTHOR INFORMATION}

\section{Corresponding Author}

*E-mail: xhxu@odu.edu; www.odu.edu/ xhxu. Tel/fax: (757) 683-5698.

ORCID

Xiao-Hong Nancy Xu: 0000-0002-7470-1948

Author Contributions

${ }^{\dagger}$ F.D., P.S., and P.K.C. contributed equally to this work.

Notes

The authors declare no competing financial interest.

\section{ACKNOWLEDGMENTS}

This work was supported in part by the NSF (CBET 0507036 and CBET 1450936) and NIH (R01 GM0764401; R21HL127580; R15 GM119116). We thank Hiroshi Yoneyama at Tohoku University, Japan, for providing three strains of Pseudomonas aeruginosa (WT, nalB-1, and $\triangle \mathrm{ABM}$ ).

\section{REFERENCES}

(1) Blair, J. M.; Piddock, L. J. Structure, function and inhibition of RND efflux pumps in Gram-negative bacteria: an update. Curr. Opin. Microbiol. 2009, 12, 512-519.

(2) Cole, S. P.; Bhardwaj, G.; Gerlach, J. H.; Mackie, J. E.; Grant, C. E.; Almquist, K. C.; Stewart, A. J.; Kurz, E. U.; Duncan, A. M.; Deeley, R. G. Overxpression of a transporter gene in a mutidrug-resistant human lung cancer cell lin. Science 1992, 258, 1650-1654.

(3) Eswaran, J.; Koronakis, E.; Higgins, M. K.; Hughes, C.; Koronakis, V. Three's company: component structures bring a closer view of tripartite drug efflux pumps. Curr. Opin. Struct. Biol. 2004, 14, 741-747.

(4) Mesaros, N.; Nordmann, P.; Plésiat, P.; Roussel-Delvallez, M.; Van Eldere, J.; Glupczynski, Y.; Van Laethem, Y.; Jacobs, F.; Lebecque, P.; Malfroot, A.; Tulkens, P. M.; Van Bambeke, F. Pseudomonas aeruginosa: resistance and therapeutic options at the turn of the new millennium. Clin. Microbiol. Infect. 2007, 13, 560-578.

(5) Seeger, M. A.; Diederichs, K.; Eicher, T.; Brandstätter, L.; Schiefner, A.; Verrey, F.; Pos, K. M. The AcrB efflux pump: conformational cycling and peristalsis lead to multidrug resistance. Curr. Drug Targets 2008, 9, 729-749.

(6) Pfister, O.; Liao, R. Pump to survive: novel cytoprotective strategies for cardiac progenitor cells. Circ. Res. 2008, 102, 998-1001.

(7) Li, X. Z.; Plesiat, P.; Nikaido, H. The challenge of efflux-mediated antibiotic resistance in Gram-negative bacteria. Clin. Microbiol. Rev. 2015, 28, 337-418.

(8) Aron, Z.; Opperman, T. J. The hydrophobic trap-the Achilles heel of RND efflux pumps. Res. Microbiol. 2017, DOI: 10.1016/ j.resmic.2017.11.001.

(9) Yang, X.; Goswami, S.; Gorityala, B. K.; Domalaon, R.; Lyu, Y.; Kumar, A.; Zhanel, G. G.; Schweizer, F. A Tobramycin Vector Enhances Synergy and Efficacy of Efflux Pump Inhibitors against Multidrug-Resistant Gram-Negative Bacteria. J. Med. Chem. 2017, 60, 3913-3932.

(10) Li, X.-Z.; Nikaido, H. Efflux-mediated drug resistance in bacteria: an update. Drugs 2009, 69, 1555-1623.

(11) Pagès, J.-M.; Amaral, L. Mechanisms of drug efflux and strategies to combat them: Challenging the efflux pump of Gramnegative bacteria. Biochim. Biophys. Acta, Proteins Proteomics 2009, 1794, 826-833.

(12) Aeschlimann, J. R. The role of multidrug efflux pumps in the antibiotic resistance of Pseudomonas aeruginosa and other gramnegative bacteria. Insights from the Society of Infectious Diseases Pharmacists. Pharmacotherapy 2003, 23, 916-924. 
(13) Giamarellou, H.; Poulakou, G. Multidrug-resistant Gramnegative infections: what are the treatment options? Drugs 2009, 69, 1879-1901.

(14) Rice, L. B. The clinical consequences of antimicrobial resistance. Curr. Opin. Microbiol. 2009, 12, 476-481.

(15) Vergidis, P. I.; Falagas, M. E. Multidrug-resistant Gram-negative bacterial infections: the emerging threat and potential novel treatment options. Curr. Opin. Investig. Drugs 2008, 9, 176-183.

(16) Germ, M.; Yoshihara, E.; Yoneyama, H.; Nakae, T. Interplay between the efflux pump and the outer membrane permeability barrier in fluorescent dye accumulation in Pseudomonas aeruginosa. Biochem. Biophys. Res. Commun. 1999, 261, 452-455.

(17) Maseda, H.; Yoneyama, H.; Nakae, T. Assignment of the substrate-selective subunits of the MexEF-OprN multidrug efflux pump of Pseudomonas aeruginosa. Antimicrob. Agents Chemother. 2000, 44, 658-664.

(18) Masuda, N.; Sakagawa, E.; Ohya, S.; Gotoh, N.; Tsujimoto, H.; Nishino, T. Substrate specificities of MexAB-OprM, MexCD-OprJ, and MexXY-oprM efflux pumps in Pseudomonas aeruginosa. Antimicrob. Agents Chemother. 2000, 44, 3322-3327.

(19) Page, M. G.; Heim, J. Prospects for the next anti-Pseudomonas drug. Curr. Opin. Pharmacol. 2009, 9, 558-565.

(20) Pietras, Z.; Bavro, V. N.; Furnham, N.; Pellegrini-Calace, M.; Milner-White, E. J.; Luisi, B. F. Structure and mechanism of drug efflux machinery in Gram negative bacteria. Curr. Drug Targets 2008, 9, 719-728.

(21) Alibert-Franco, S.; Pradines, B.; Mahamoud, A.; Davin-Regli, A.; Pagès, J. M. Efflux mechanism, an attractive target to combat multidrug resistant Plasmodium falciparum and Pseudomonas aeruginosa. Curr. Med. Chem. 2009, 16, 301-317.

(22) Akama, H.; Kanemaki, M.; Yoshimura, M.; Tsukihara, T.; Kashiwagi, T.; Yoneyama, H.; Narita, S.; Nakagawa, A.; Nakae, T. Crystal structure of the drug discharge outer membrane protein, OprM, of Pseudomonas aeruginosa: dual modes of membrane anchoring and occluded cavity end. J. Biol. Chem. 2004, 279, 52816-52819.

(23) Akama, H.; Matsuura, T.; Kashiwagi, S.; Yoneyama, H.; Narita, S.; Tsukihara, T.; Nakagawa, A.; Nakae, T. Crystal structure of the membrane fusion protein, MexA, of the multidrug transporter in Pseudomonas aeruginosa. J. Biol. Chem. 2004, 279, 25939-25942.

(24) Wilke, M. S.; Heller, M.; Creagh, A. L.; Haynes, C. A.; McIntosh, L. P.; Poole, K.; Strynadka, N. C. The crystal structure of MexR from Pseudomonas aeruginosa in complex with its antirepressor ArmR. Proc. Natl. Acad. Sci. U. S. A. 2008, 105, 14832-14837.

(25) Greenwood, D. Modes of action in antibiotic and chemotherapy. In Antibiotic and Chemotherapy: Anti-infective Agents and Their Use in Therapy, 7th ed.; O'Grady, F., Lambert, H. P., Finch, R. G., Greenwood, D., Eds.; Churchill, Livingstone: New York, 1997; pp 122.

(26) Moreno-Sastre, M.; Pastor, M.; Salomon, C. J.; Esquisabel, A.; Pedraz, J. L. Pulmonary drug delivery: a review on nanocarriers for antibacterial chemotherapy. J. Antimicrob. Chemother. 2015, 70, 29452955.

(27) Perni, S.; Prokopovich, P. Continuous release of gentamicin from gold nanocarriers. RSC Adv. 2014, 4, 51904-51910.

(28) Skwarecki, A. S.; Milewski, S.; Schielmann, M.; Milewska, M. J. Antimicrobial molecular nanocarrier-drug conjugates. Nanomedicine 2016, 12, 2215-2240.

(29) Xu, X.-H. N.; Kyriacou, S.; Jeffers, R. Metallic Nanoparticles for Inhibition of Bacterium Growth. U.S. Patent App. US20030108612A1, 2002.

(30) Jain, P. K.; Huang, X.; El-Sayed, I. H.; El-Sayed, M. A. Noble metals on the nanoscale: optical and photothermal properties and some applications in imaging, sensing, biology, and medicine. Acc. Chem. Res. 2008, 41, 1578-1586.

(31) Kreibig, U.; Vollmer, M. In Optical Properties of Metal Clusters; Springer: Berlin, 1995; pp 14-123.
(32) Nallathamby, P. D.; Huang, T.; Xu, X.-H. N. Design and characterization of optical nano rulers of single nanoparticles using optical microscopy and spectroscopy. Nanoscale 2010, 2, 1715-1722.

(33) Nallathamby, P. D.; Lee, K. J.; Desai, T.; Xu, X.-H. N. Study of multidrug membrane transporters of single living pseudomonas aeruginosa cells using size-dependent plasmonic nanoparticle optical probes. Biochemistry 2010, 49, 5942-5953.

(34) Nallathamby, P. D.; Lee, K. J.; Xu, X.-H. N. Design of stable and uniform single nanoparticle photonics for in vivo dynamics imaging of nanoenvironments of zebrafish embryonic fluids. ACS Nano 2008, 2, $1371-1380$.

(35) Schultz, S.; Smith, D. R.; Mock, J. J.; Schultz, D. A. Single-Target Molecule Detection With Nonbleaching Multicolor Optical Immunolabels. Proc. Natl. Acad. Sci. U. S. A. 2000, 97, 996-1001.

(36) Xu, X.-H. N.; Chen, J.; Jeffers, R. B.; Kyriacou, S. V. Direct measurement of sizes and dynamics of single living membrane transporters using nano-optics. Nano Lett. 2002, 2, 175-182.

(37) Huang, T.; Nallathamby, P. D.; Gillet, D.; Xu, X.-H. N. Design and synthesis of single nanoparticle optical biosensors for imaging and characterization of single receptor molecules on single living cells. Anal. Chem. 2007, 79, 7708-7718.

(38) Huang, T.; Nallathamby, P. D.; Xu, X.-H. N. Photostable singlemolecule nanoparticle optical biosensors for real-time sensing of single cytokine molecules and their binding reactions. J. Am. Chem. Soc. 2008, 130, 17095-17105.

(39) Lee, K. J.; Nallathamby, P. D.; Browning, L. M.; Osgood, C. J.; $\mathrm{Xu}, \mathrm{X} . \mathrm{H}$. N. In vivo imaging of transport and biocompatibility of single silver nanoparticles in early development of zebrafish embryos. ACS Nano 2007, 1, 133-143.

(40) Kyriacou, S. V.; Brownlow, W. J.; Xu, X. H. N. Using nanoparticle optics assay for direct observation of the function of antimicrobial agents in single live bacterial cells. Biochemistry 2004, 43, 140-147.

(41) Xu, X.-H. N.; Brownlow, W. J.; Kyriacou, S. V.; Wan, Q.; Viola, J. J. Real-time probing of membrane transport in living microbial cells using single nanoparticle optics and living cell imaging. Biochemistry 2004, 43, 10400-10413.

(42) Browning, L. M.; Lee, K. J.; Nallathamby, P. D.; Cherukuri, P. K.; Huang, T.; Warren, S.; Xu, X.-H. N. Single nanoparticle plasmonic spectroscopy for study of charge-dependent efflux function of multidrug $\mathrm{ABC}$ transporters of single live Bacillus subtilis cells. $J$. Phys. Chem. C 2016, 120, 21007-21016.

(43) Browning, L. M.; Lee, K. J.; Cherukuri, P. K.; Nallathamby, P. D.; Warren, S.; Jault, J.-M.; Xu, X.-H. N. Single nanoparticle plasmonic spectroscopy for study of efflux function of multidrug $\mathrm{ABC}$ membrane transporters of single live cells. RSC Adv. 2016, 6, 36794-36802.

(44) Browning, L. M.; Lee, K. J.; Huang, T.; Nallathamby, P. D.; Lowman, J.; Xu, X.-H. N. Random walk of single gold nanoparticles in zebrafish embryos leading to stochastic toxic effects on embryonic developments. Nanoscale 2009, 1, 138-152.

(45) Xu, X.-H. N.; Song, Y.; Nallathamby, P. D. Probing Membrane Transport of Single Live Cells Using Single Molecule Detection and Single Nanoparticle Assay. In New Frontiers in Ultrasensitive Bioanalysis: Advanced Analytical Chemistry Applications in Nanobiotechnology, Single Molecule Detection, and Single Cell Analysis; Xu, X.-H. N., Ed.; Wiley: NJ, 2007; pp 41-65.

(46) Huang, T.; Browning, L. M.; Xu, X.-H. N. Far-field photostable optical nanoscopy (PHOTON) for real-time super-resolution singlemolecular imaging of signaling pathways of single live cells. Nanoscale 2012, 4, 2797-2812.

(47) Huang, T.; Xu, X.-H. N. Multicolored nanometer-resolution mapping of single protein-ligand binding complex using far-field photostable optical nanoscopy (PHOTON). Nanoscale 2011, 3, $3567-3572$.

(48) Huang, T.; Xu, X.-H. N. Synthesis and characterization of tunable rainbow colored silver nanoparticle solutions using singlenanoparticle plasmonic microscopy and spectroscopy. J. Mater. Chem. 2010, 20, 9867-9876. 
(49) Morgan, A. R.; Lee, J. S.; Pulleyblank, D. E.; Murray, N. L.; Evans, D. H. Review: ethidium fluorescence assays. part 1. physicochemical studies. Nucleic Acids Res. 1979, 7, 547-569.

(50) Kyriacou, S. V.; Nowak, M. E.; Brownlow, W. J.; Xu, X.-H. N. Single live cell imaging for real-time monitoring of resistance mechanism in pseudomonas aeruginosa. J. Biomed. Opt. 2002, 7, $576-586$.

(51) Ocaktan, A.; Yoneyama, H.; Nakae, T. Use of fluorescence probes to monitor function of the subunit proteins of the MexAMexB-OprM drug extrusion machinery in Pseudomonas aeruginosa. J. Biol. Chem. 1997, 272, 21964-21969.

(52) Xu, X.-H. N.; Brownlow, W. J.; Huang, S.; Chen, J. Real-time measurements of single membrane pump efficiency of single living pseudomonas aeruginosa cells using fluorescence microscopy and spectroscopy. Biochem. Biophys. Res. Commun. 2003, 305, 79-86.

(53) Xu, X.-H. N.; Wan, Q.; Kyriacou, S. V.; Brownlow, W. J.; Nowak, M. E. Direct observation of substrate induction of resistance mechanism in Pseudomonas aeruginosa using single live cell imaging. Biochem. Biophys. Res. Commun. 2003, 305, 941-949.

(54) Ding, F.; Lee, K. J.; Vahedi-Faridi, A.; Yoneyama, H.; Osgood, C. J.; Xu, X.-H. N. Design and study of the efflux function of the EGFP fused MexAB-OprM membrane transporter in Pseudomonas aeruginosa using fluorescence spectroscopy. Analyst 2014, 139, 3088-3096.

(55) Nakae, T.; Nakajima, A.; Ono, T.; Saito, K.; Yoneyama, H. Resistance to beta-lactam antibiotics in Pseudomonas aeruginosa due to interplay between the MexAB-OprM efflux pump and betalactamase. Antimicrob. Agents Chemother. 1999, 43, 1301-1303.

(56) Yoneyama, H.; Ocaktan, A.; Tsuda, M.; Nakae, T. The role of mex-gene products in antibiotic extrusion in Pseudomonas aeruginosa. Biochem. Biophys. Res. Commun. 1997, 233, 611-618.

(57) Berney, M.; Hammes, F.; Bosshard, F.; Weilenmann, H. U.; Egli, T. Assessment and Interpretation of Bacterial Viability By Using The LIVE/DEAD Baclight Kit In Combination With Flow Cytometry. Appl. Environ. Microbiol. 2007, 73, 3283-3290.

(58) Huang, T.; Cao, W.; Elsayed-Ali, H. E.; Xu, X. H. N. Highthroughput ultrasensitive characterization of chemical, structural and plasmonic properties of EBL-fabricated single silver nanoparticles. Nanoscale 2012, 4, 380-385.

(59) Browning, L. M.; Lee, K. J.; Nallathamby, P. D.; Xu, X.-H. N. Silver nanoparticles incite size and dose-dependent developmental phenotypes and nanotoxicity in zebrafish embryos. Chem. Res. Toxicol. 2013, 26, 1503-1513.

(60) Nallathamby, P. D.; Xu, X.-H. N. Study of cytotoxic and therapeutic effects of stable and purified silver nanoparticles on tumor cells. Nanoscale 2010, 2, 942-952.

(61) Lee, K. J.; Browning, L. M.; Huang, T.; Ding, F.; Nallathamby, P. D.; Xu, X.-H. N. Probing of multidrug ABC membrane transporters of single living cells using single plasmonic nanoparticle optical probes. Anal. Bioanal. Chem. 2010, 397, 3317-3328. 